\title{
Simulation Analysis of Knowledge Transfer in a Knowledge Alliance Based on a Circular Surface Radiator Model
}

\author{
Yi Su $\mathbb{D I}^{1,2}$ and Tianchi $\mathrm{Li}^{1}$ \\ ${ }^{1}$ School of Economics and Management, Harbin Engineering University, Harbin 150001, China \\ ${ }^{2}$ School of Management, University of Bradford, Bradford, UK \\ Correspondence should be addressed to Yi Su; suyi@hrbeu.edu.cn
}

Received 3 September 2019; Revised 10 April 2020; Accepted 6 May 2020; Published 27 May 2020

Academic Editor: Honglei Xu

Copyright (C) 2020 Yi Su and Tianchi Li. This is an open access article distributed under the Creative Commons Attribution License, which permits unrestricted use, distribution, and reproduction in any medium, provided the original work is properly cited.

\begin{abstract}
Based on the theory of acoustic waves, a circular surface radiator model is introduced as a basis for constructing a knowledge transfer model for a knowledge alliance. The three main variables in the model are chosen to be the number of enterprises in knowledge alliance, the frequency of knowledge transfer, and the relationship distances between the knowledge bodies. The internal mechanism of knowledge transfer in a knowledge alliance is studied, and the direct relationships among the internal influencing factors are explored. The results show that the number of enterprises in knowledge alliance, knowledge transfer frequency, and knowledge transfer effect are positively correlated. The "Rayleigh distance" in the knowledge field is the appropriate relationship distance measure for assessing knowledge transfer within the alliance. The Rayleigh distance is highly correlated with the number of enterprises in knowledge alliance and knowledge transfer frequency. Moreover, the number of enterprises in knowledge alliance and knowledge transfer frequency are interrelated.
\end{abstract}

\section{Introduction}

With the advent of the knowledge economy era, knowledge resources have replaced traditional resources such as capital and land as the most valuable strategic resources for enterprises. Through the absorption and application of knowledge resources, enterprises can produce new products on the basis of newly developed technologies to ensure core competitiveness. With the rapid growth and evolution of the $\mathrm{R} \& \mathrm{D}$ costs for technology, enterprises have difficulty in achieving all of their resource development needs alone. An increasing number of enterprises are recognizing that building knowledge alliances with other enterprises can enhance each individual enterprise's core competencies and help to sustain its long-term competitive advantage. By this means, enterprises can integrate complementary knowledge resources through communication, acquire key technical resources, and then generate new knowledge and integrate existing knowledge [1-2]. However, China's intellectual property system is imperfect, and a corresponding support system has not yet been fully established. Thus, the general situation in knowledge alliances is that "there is transfer behaviour but no transfer effect" [4]. This problem needs to be solved to guide reasonable cooperation among the enterprises participating in knowledge alliances and enhance the effect of knowledge transfer within these knowledge alliances. Knowledge transfer has specific effects and follows certain laws. Studying and mastering these laws can guide enterprises in carrying out cooperative innovation and in improving the effects of knowledge transfer.

The definition of a knowledge alliance proposed by Inkpen in 1995 is still used today. He believed that a knowledge alliance is a kind of strategic alliance that creates valuable new knowledge through knowledge transfer and knowledge integration. On the basis of Inkpen's work, various scholars have subsequently presented their own views on the purpose of forming a knowledge alliance [5]. In general, it is believed that the purpose of forming a knowledge alliance is to serve both overall and personal interests, create invisible knowledge through cooperation, 
and build long-term cooperation in learning and research $[6,7]$. A knowledge alliance is an effective way for enterprises to cultivate core competence. Such an alliance has the characteristics of spreading and creating knowledge, attracting wide participation, engendering close relationships among members, and fostering complementarity [8]. Creating new knowledge through mutual learning among knowledge subjects is the core goal of a knowledge alliance [9]. The similarities between domain knowledge and structural knowledge affect the probability of the formation of a knowledge alliance [10]. The development process of a knowledge alliance is continuous and gradual. As an emerging class of knowledge alliances, industry-academic knowledge alliances have the characteristics of independent innovation capabilities and flexible organizational structures [11].

In the process of establishing knowledge alliances to acquire knowledge to enhance core competitiveness, there are many factors that affect knowledge transfer both inside and outside an organization. Many scholars have conducted in-depth research on this topic that has yielded rich research results [12-16]. From the information network perspective, an instance of knowledge transfer within a knowledge alliance can be divided into five dimensions: the knowledge source, the transferred knowledge, the knowledge acceptor, the transfer medium, and the transfer situation. The willingness to engage in knowledge transfer and the transfer opportunities of both the knowledge source and the knowledge acceptor influence the effect of knowledge transfer, whereas the absorption capacity of the knowledge acceptor largely determines the efficiency of knowledge transfer [17-21]. The implicitness, fuzziness, complexity, and embedding of knowledge transfer also have an impact on efficiency, and the transfer medium and transfer situation are also important factors affecting the transfer process $[16,22,23]$. In recent years, many scholars have also studied knowledge transfer in knowledge alliances from the perspective of social networks [24-27]. At present, some theoretical studies have investigated the direct influence of social network embedding on knowledge transfer behaviour from the perspectives of network characteristics and quality, transfer ability, and opportunity. Some scholars have explored the relationship between team social networks and knowledge transfer [28-30]. Scholars have extensively discussed the impact of channel fairness on channel members' knowledge transfer. In particular, some differences in channel fairness or channel power can even have a positive impact on knowledge transfer [31,33]. Interaction, social relationship dimensions, knowledge diversity, random diffusion, and parallel replication are all important factors influencing knowledge transfer in social networks [34-36]. Knowledge transfer in social networks has scale-free and small-world characteristics, and scale-free networks are more conducive to knowledge transfer than conventional networks are [37-41]. The forgetting and self-learning mechanisms in social networks also have an important impact on the knowledge transfer process [42-44]. The fundamental objective of knowledge transfer is to promote the knowledge and ability levels of the recipients. Therefore, seeking ways to improve the performance of knowledge transfer by analysing its underlying mechanism has become an important focus of research. Scholars have noted that relationship management and knowledge management are key for improving knowledge transfer performance and that knowledge alliances must therefore establish strategies and open cultures to support integration [45, 46]. Many scholars have studied the mechanism of knowledge transfer in knowledge alliances by establishing various models. Based on these models, scholars have found that knowledge transfer ability, background similarity, knowledge complementarity, absorption ability, the shared vision of a alliance, knowledge feedback, and the communication atmosphere are positively correlated with the transfer effect, while the degrees of knowledge blur and complexity are negatively correlated with the transfer effect [47-50]. The distances, relationships, and knowledge transfer times between knowledge subjects are the main factors affecting the performance of knowledge transfer [15, 42, 51-53]. The knowledge depth of a knowledge alliance and the Doppler effect of knowledge waves are also closely related to knowledge transfer [55]. The willingness to communicate among the enterprises participating in a knowledge alliance will gradually increase in the early stage, when the knowledge gap is large, and then gradually stabilizes or even declines with knowledge exchange. The absorptive capacity of the receiving enterprise determines the corresponding transfer strategy, and an ability to integrate the knowledge gained from the knowledge source is critical in the application stage [56].

In summary, a great deal of research has been conducted on the characteristics of knowledge alliances and the motivation for their formation, the factors affecting knowledge transfer, and the mechanism and performance of knowledge transfer in knowledge alliances, and this research has yielded meaningful conclusions. The process of knowledge transfer is complicated, and it is difficult to explore the complex interactions among many influencing factors. Using theories and models of other disciplines to build metaphor models can provide new methods and inspiration for dealing with complex system problems, but the current research on knowledge transfer using metaphor research methods is rare. In addition, the current research has not paid sufficient attention to the influence of the number of enterprises within a knowledge alliance, and models are unlikely to consider multiple directions and angles in the process of knowledge transfer.

The process of knowledge transfer is affected by many factors. This paper mainly studies the influencing factors on the process of knowledge transfer from three aspects: the transfer subject dimension, the transfer behaviour dimension, and the transfer context dimension. Other influencing factors are interrelated and implicit with the three dimensions. The number of enterprises in knowledge alliance is the representation of the transfer subject dimension. Factors such as the amount of knowledge in the alliance, the level of knowledge recognition, and the complexity of the alliance relationship are all related to it. The frequency of knowledge transfer is a representation of the transfer behaviour 
dimension. The speed of knowledge transfer is related to the connection frequency among enterprises, and the willingness of knowledge transfer will also affect the frequency of knowledge transfer. Relationship distance is a representation of the transfer context dimension, which describes the objective state of the relationship between the subjects of knowledge transfer. The distance of the relationship also affects the methods adopted by enterprises in the transfer process, such as commissioned research, consulting, or professional meetings. At the same time, this paper uses a metaphorical research method to introduce a knowledge circular radiator model in acoustics. Besides the similarity between the research subject and the metaphorical model, the similarity between the metaphorical variables and the variables in the model should also be guaranteed. The size of sound source, the frequency of sound emission, and the distance are, respectively, metaphorized as the number of enterprises in the knowledge alliance, the frequency of knowledge transfer, and the distance of relationship, which is reasonable in physical hypothesis and metaphorical logic.

\section{Knowledge Transfer Model for a Knowledge Alliance}

2.1. Research Method. The knowledge transfer process in knowledge alliance is complicated, and the knowledge transfer system is a complex system. Each element in a complex system is interrelated and interdependent. According to the viewpoint of system science, the complex system can be simplified by abstracting the complex system and extracting the key elements in the system. Studying complex systems with the help of models from other disciplines helps to find the complex correlations among influencing factors, as well as the underlying laws in the system. This paper mainly studies the influencing factors on the process of knowledge transfer from three aspects: the transfer subject dimension, the transfer behaviour dimension, and the transfer context dimension. Through the application of metaphor and acoustic model, the knowledge transfer problem is abstracted into three dimensions of variables.

Complexity science mainly focuses on the complexity phenomenon and its evolution of research objects. By exploring the commonalities of complex phenomena such as nature, society, organization, thinking, and cognition, it helps people to understand various complex phenomena more comprehensively and manage them accurately. Complexity is an objective reality. Scholars have different definitions of complexity, but their understanding of the connotation of complex systems is similar. Complexity systems are characterized by diversity, hierarchy, nonlinearity, and openness [57]. Knowledge transfer has influential factors in different dimensions, such as the subject of knowledge transfer, the context of knowledge transfer, and knowledge transfer behaviour. Subsystems and elements of different dimensions are interrelated and constrained each other. Nonlinear effects occur in one or more ways, and the ways of interaction are diverse. The knowledge transfer system has not only the characteristics of information networks but also the characteristics of social networks. The diversity and differences of the subsystems and influencing factors constitute a complex multilevel structure. In the process of knowledge transfer, the subject of knowledge transfer and the surrounding environment are constantly exchanging material, information, and energy. This shows that the knowledge transfer system is an open system. Studying the complexity of knowledge transfer is helpful to provide new ideas and countermeasures for improving the efficiency of knowledge transfer and has guiding significance for the practice of knowledge transfer.

Metaphor is a common research approach in scientific fields of complexity. This approach can transform complex systems, through simile or analogy, into intuitive concepts expressed in simple language [57]. A metaphor is a conceptual representation of one empirical domain based on another empirical domain. As a paradigm of scientific representation, metaphors play a fundamental role in establishing connections between scientific language and the real world [58]. Metaphors can often be used to reduce complex problems in unknown domains into simpler problems. The redescription of certain parts of reality through metaphor provides a new mode of cognition for scientific research. The cognitive history of the human exploration of nature shows that metaphor plays an irreplaceable role in the scientific interpretation and innovation of scientific theory [59-61]. The emergence of scientific concepts and the construction of scientific theories embody the metaphorical features of scientific thinking. Metaphor enriches people's understanding of the scientific world and offers new possibilities for the practice of scientific theory by juxtaposing unfamiliar and even difficult-to-describe objects and phenomena with well-known and directly described manifest facts. In this way, a similarity is created between the two juxtaposed contexts, and on this basis, a new cognitive concept is formed $[62,63]$. A metaphor represents a highlevel or somewhat abstract connection between concepts, the purpose of which is not precision but similarity [64]. This similarity does not imply a direct similarity between the two things themselves but rather a similarity of the relationship between the two. The application of metaphor and metaphor models in the practice of scientific representation has obvious cognitive advantages. A scientific model based on a scientific metaphor can better characterize the structure of the material world. It provides the best explanation for the assumptions made by scientists about the world [59]. The construction of a scientific model based on metaphorical thinking involves three aspects: differences of metaphor models in different situations, metaphorical accuracy, and similarity in metaphorical object structure. Due to the similarity between the metaphor model system and the target system and the particularity of the model description, the main characteristics of such a metaphor model are contextual relevance, dynamic hierarchy, and theoretical constructivity [65]. In the actual construction of a metaphor model, the three basic problems involved are the intentionality of the modelling subject, the representational relationship between the metaphor model and the target object, and the real problem of interest for the modelling 
object [66]. Since the second half of the 20th century, the study of scientific models from a metaphorical perspective has received widespread attention from scientists ([67-70]; Ritchie, 2006). American scholar Michael Bradie's 1999 paper "Science and Metaphor" and American scholar Theodore L. Brown's "Making Truth: Metaphor in Science" $[59,71]$ both note that metaphor is an essential element of scientific theorization that plays an important role in scientific proofs and the deduction of scientific theories and theoretical interpretations, thus illustrating the metaphorical nature of scientific reasoning and scientific communication. Subsequent scholars have further developed the metaphorbased research approach and applied it in various fields of natural science [72-75].

Metaphor-based scientific modelling is based on an analogy between the model and the target object. By seeking commonalities in terms of physical properties, a real physical model can be applied to better understand another real system [76]. The relationships among the various contextual elements involved in the metaphorical reasoning process are integrated, and on this basis, the integrated relationships are presented through model construction. The metaphor modelling process can be described as the process of "scanning" the elements of a problem in the relevant context to seek the commonalities between the base model and the target, mapping these common orientations to the target object and further establishing a model representation based on this similarity. The essence of scientific modelling based on metaphor is the creation of a set of mapping relationships between two domains [66]. The basic mapping procedure consists of formulating a detailed description of an unknown object on the basis of similarity by analogy between the structure and characteristics of the metaphor's ontology and the metaphor itself [65]. Based on this approach, this paper will discuss the metaphorical relationship between knowledge transfer in a knowledge alliance and vibrational acoustics from two perspectives: feature mapping and structure mapping.

First, let us consider the feature mapping between knowledge transfer in a knowledge alliance and acoustic wave transfer in an acoustic medium. Both knowledge and acoustic waves are transitive. The transmission of both knowledge and acoustic waves involves senders and receivers, and the transmitted knowledge or acoustic waves must be consistent with the receivers' capabilities. In the case of knowledge transfer in a knowledge alliance, there may be multiple knowledge senders simultaneously transferring knowledge, resulting in a superposition of knowledge transfer for a single knowledge receiving enterprise; acoustic wave transfer also has the same characteristics. The process of knowledge transfer is affected by many factors. Knowledge cannot be transmitted to a knowledge receiving enterprise completely and without distortion. Similarly, acoustic wave transfer is also subject to interference from noise. The acoustic signal received by a receiving source may be partially lost, causing attenuation during transmission.

Second, let us consider the structural mapping between knowledge transfer in a knowledge alliance and acoustic wave transfer in an acoustic medium. In the theory of acoustic waves, the vibration of a sound source is the source of acoustic waves. In the case of knowledge transfer in a knowledge alliance, a knowledge source possessing relevant knowledge is also continuously transmitting knowledge. The knowledge transfer process can be understood as a process in which a knowledge-sending enterprise continuously generates knowledge waves through constant vibration and continuously influences one or more knowledge receiving enterprises in the form of waves. In a knowledge alliance, a knowledge-sending enterprise sends knowledge waves to the knowledge receiving enterprises in the surrounding space. Similarly, a sound source also sends acoustic waves out into its surroundings. Both scenarios are consistent with the concept of a "field" [77]. In the process of acoustic wave transmission, the distance from the source to the receiver is an important factor influencing the effect of acoustic wave transmission. In the process of knowledge transfer in a knowledge alliance, the relationship distance between the knowledge-sending and knowledge receiving enterprises also has an important influence on the effect of knowledge transfer. In a knowledge transfer environment, various favourable factors exist that may promote knowledge transfer, such as policies. Similarly, the medium in an acoustic environment also affects the transmission of acoustic waves.

From the above analogy between knowledge transfer and acoustic wave transmission, it can be seen that they have many similarities. Therefore, it is scientific and reasonable to use the theory of acoustic waves to construct a knowledge transfer model by mapping the concepts and research methods of acoustic wave theory to the case of knowledge transfer in knowledge alliances. The remainder of this paper will describe a metaphor model for knowledge transfer in knowledge alliances based on a circular radiator model from acoustic wave theory. The process of knowledge transfer in a knowledge alliance is a process by which a knowledge source spreads knowledge waves to surrounding target enterprises and the knowledge receiving enterprises receive and absorb these knowledge waves [77]. Here, the knowledge source is considered to be composed of all relevant knowledge bodies in the knowledge alliance. Whenever the relevant knowledge to be shared via the knowledge transfer process changes, the knowledge source also changes. Two types of related knowledge are involved in the knowledge transfer process: core-related knowledge and noncore-related knowledge. Other irrelevant knowledge held by other enterprises in the knowledge alliance does not participate in this knowledge transfer process. The core-related knowledge is the most critical knowledge in the knowledge transfer process. An enterprise that fully grasps the core knowledge is called a core enterprise. Noncore-related knowledge consists of any other knowledge that is related to the core knowledge. Enterprises that do not yet fully grasp the core knowledge but have mastered some noncore knowledge are called noncore enterprises. Among the enterprises, the core enterprises can transfer knowledge most accurately and completely; by contrast, the knowledge held by noncore enterprises is relatively weakly related to the core 
knowledge because these noncore enterprises have insufficient mastery of the core knowledge. Therefore, knowledge transfer from noncore enterprises can be affected by other knowledge transfer processes being carried out by the enterprise, potentially resulting in the distortion of knowledge. The weaker the degree of association between the noncore knowledge and the core knowledge is, the more likely it is that knowledge distortion and bias will arise during knowledge transfer. We find that there are two key characteristics of the knowledge transfer process in a knowledge alliance: (1) the core knowledge has the most direct impact on a knowledge receiving enterprise; (2) the knowledge transfer of knowledge sources and knowledge receiving enterprises is directional, and the closer the knowledge transfer to the core knowledge, the closer the knowledge transfer is to the "direction". The physics assumptions of a model of the acoustic radiation of a circular radiator in an infinite plane baffle (referred to as a circular radiator model for brevity) in acoustic wave theory are in good agreement with these characteristics of knowledge transfer in a knowledge alliance. In such a circular radiator model, the sound source is a circular radiator embedded in an infinite plane baffle. Due to the presence of the baffle, the sound source radiates acoustic waves only into a semiinfinite space. This model mainly considers the relationship between a point in space and the centre of the sound source and the sound pressure at that point (in a sense, acoustic waves intensity at the point of interest). For the construction of a metaphor model, all knowledge subjects involved in the process of knowledge transfer in a knowledge alliance can be placed in a circle of knowledge sources, called the circular knowledge radiator. The core knowledge is located at the centre of the circle, and the noncore knowledge surrounds the centre of the circle. The higher the degree of association between a noncore body and the core knowledge, the closer the body is to the centre of the circle. The greater the number of knowledge subjects associated with the core knowledge in the knowledge alliance, the larger the radius of the circular knowledge radiator. If a knowledge receiving enterprise is located on the central axis of the circular knowledge radiator, this indicates that the core knowledge has a direct impact on the receiving enterprise. In contrast, if there is a certain angle between the central axis of the radiator and the knowledge receiving enterprise, noncore knowledge will also have an indirect impact on the receiving enterprise. The farther away from the centre of the circle a knowledge receiving enterprise is, the greater the angle is. The distance between the knowledge receiving enterprise and the centre of the circular knowledge radiator corresponds to the relationship distance between the knowledge sending enterprise and the knowledge receiving enterprise, and the range of this relationship distance is $(0,+\infty)$. As the distance between the knowledge-receiving enterprise and the knowledge alliance decreases, the indirect impact of the noncore knowledge on the receiving enterprise will increase. The relationship between the core knowledge, the noncore knowledge, and the knowledge receiving enterprises in a knowledge alliance is illustrated in Figure 1.
FIGURE 1: Relationship diagram of core/noncore knowledge and knowledge receiving enterprises in a knowledge alliance. 1, core knowledge; 2, noncore knowledge; 3, knowledge receiving enterprise.

2.2. Model Construction. As discussed in the previous section, it is reasonable and feasible to introduce a circular radiator model into research on knowledge transfer in knowledge alliances. In this section, a knowledge transfer model for a knowledge alliance is constructed using this circular radiator model, and the parameters and concepts of acoustics waves theory are introduced to explore the internal mechanism of knowledge transfer. The constructed model is called the circular knowledge radiator model. It is assumed that each point on the circular knowledge radiator is a related knowledge body involved in the knowledge transfer process and that these bodies transfer knowledge to knowledge receiving enterprises. In accordance with the principle of the superposition of waves, the knowledge wave received at the point corresponding to a knowledge receiving enterprise is a superposition of the knowledge transferred from each knowledge body in the circular knowledge radiator to the knowledge receiving enterprise.

If we wish to consider the influence of the circular knowledge radiator on any point in the knowledge field, we need to establish a spherical coordinate system with its origin at the centre of the circular knowledge radiator. This system is represented by the spherical coordinates $(r, \theta)$, where $\theta$ represents the angle between any point $M$ in the knowledge field and the axis of the circular knowledge radiator and $r$ represents the distance between the point $M$ and the centre of the circular knowledge radiator. $S$ denotes the circular face of the knowledge radiator, which is of radius $a$; $d s$ denotes a microelement of the circular knowledge radiator, representing any single knowledge subject; and $r_{A}$ is the distance from such a microelement to a point of interest in the knowledge field, as shown in Figure 2.

A polar coordinate system $(O-\rho-\varphi)$ is also defined on the circular knowledge radiator. As shown in Figure 3, the point $P$ is the point on the plane of the circular knowledge radiator onto which the point $M$ is projected. The angle between $O P$ and the line connecting $d s$ and $O$ is $\varphi$, and $d s=\rho d \varphi d p$. 


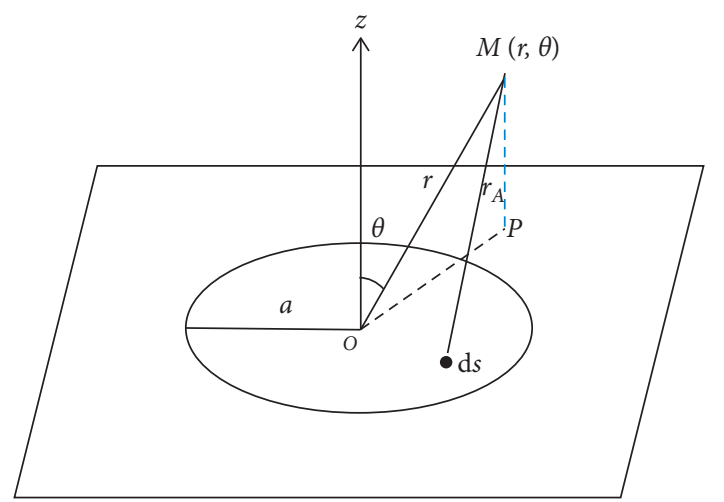

FIGURE 2: Coordinate frame for a circular knowledge radiator.

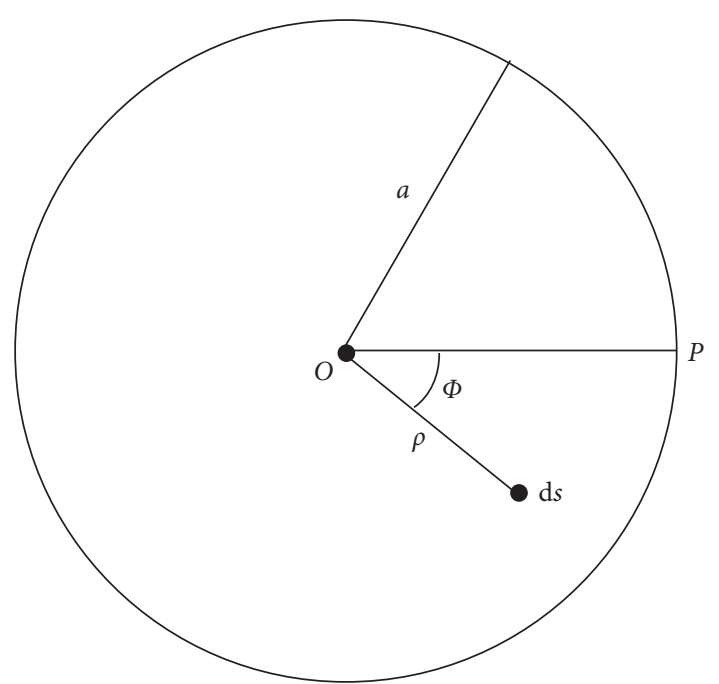

Figure 3: Polar coordinate frame on the circular knowledge radiator.

In the circular radiator model, the function describing the sound pressure amplitude distribution at any point in the sound field can be obtained from the velocity potential of the sound source. The sound pressure amplitude reflects the intensity of the sound field at a certain point. When mapped to the case of knowledge transfer in a knowledge alliance, this amplitude can be understood as the influence of the knowledge source at a certain point in the knowledge field.

The velocity potential of a circular knowledge radiator is known to be

$$
\Phi(r)=e^{j \omega t} \iint_{S} \frac{v_{0}}{2 \pi} \frac{e^{-j k r_{A}}}{r_{A}} \mathrm{~d} s .
$$

$v_{0}$ represents the level of knowledge that the knowledge alliance is willing to transfer at a certain time. Importantly, enterprises generally do not share their core technologies with each other but instead cooperate with each other more in noncore areas. $k$ represents the knowledge wave number of the circular knowledge radiator, that is, the number of complete knowledge wave periods in a length of $2 \pi$. $\omega$ represents the speed of innovation in the enterprises participating in the knowledge alliance.

Thus, according to

$$
p(r)=\rho_{0} \frac{\partial \Phi(r)}{\partial r},
$$

we can obtain the distribution function describing the influence of the knowledge alliance in the knowledge field as follows:

$$
p(r)=\frac{j \omega \rho_{0} a^{2} v_{0} e^{j(\omega t-k r)}}{2 r} \frac{2 J_{1}(k a \sin \theta)}{(k a \sin \theta)},
$$

where $p(r)$ denotes the influence of the circular knowledge radiator on knowledge transfer at any point in the knowledge field and $\rho_{0}$ denotes the density of the environment, which affects the diffusion of knowledge waves.

The knowledge wave number is an important concept. Based on the knowledge wave number, we can obtain many variables related to knowledge wave transfer to characterize the specific knowledge transfer situation, such as the knowledge wave frequency $f$, the knowledge wavelength $\lambda$, the knowledge wave cycle $T$, and the knowledge wave velocity $c$, where the knowledge wave frequency $f$ and the knowledge wave cycle $T$ are reciprocal to each other, that is, $f=1 / T$. The knowledge wave frequency $f$ represents the number of knowledge waves sent per unit time. The knowledge wave cycle $T$ represents how long it takes to send a knowledge wave. The knowledge wave velocity $c$ represents the speed of knowledge wave propagation in the environment. The knowledge wavelength $\lambda$ represents the distance travelled by a knowledge wave over the course of one period. Clearly, the relationship among $c, f$, and $\lambda$ is $c=f \lambda$. The knowledge wave number $k$ represents the number of knowledge wave periods within the length of $2 \pi$, that is, $k=2 \pi / \lambda$; through variable substitution, $k=2 \pi / \lambda$ can be obtained. The relationship between the knowledge wave angular frequency $\omega$ and the knowledge wave frequency $f$ is $\omega=2 \pi f=2 \pi / T$. Therefore, the knowledge wave angular frequency $\omega$ can also be understood as the number of complete knowledge wave periods produced in a time duration of $2 \pi$. The knowledge wave angular frequency $\omega$, the knowledge wave frequency $f$, and the knowledge wave number $k$ are closely related. Through substitution, expressions written in terms of these quantities can instead be expressed in terms of the knowledge wavelength $\lambda$ and the knowledge wave velocity $c$.

From formula (3), we can observe that this influence distribution function varies with $\theta$ in addition to $r$. That is, at the same distance in space, the distribution of the knowledge influence is different at different angles. Taking $\theta=0^{\circ}$ as the initial direction value, a knowledge field directivity function $\Phi$ can be obtained by normalizing the knowledge influence distribution function for different angles:

$$
D(\theta)=\frac{|\widetilde{p}(z, \theta)|}{|\widetilde{p}(z, \theta=0)|}=\left|\frac{2 J_{1}(k a \sin \theta)}{(k a \sin \theta)}\right| .
$$

It can be found that formula (3) contains too many variables, which makes it too complicated to carry out 
simulation research directly. Therefore, the formula needs to be simplified to a certain extent and explore the internal mechanism of knowledge transfer by studying the changes in several core variables. Based on this, this paper assumes that, during the process of knowledge transfer, the target knowledge receiving enterprise is on the central axis of the knowledge circular radiator. This means that the target knowledge receiving enterprise corresponds to this knowledge transfer and has the highest matching degree with this knowledge transfer. The selection of coordinate axes can be simplified in Figure 4.

The velocity potential function in the knowledge field is known to be

$$
\Phi(r)=e^{j \omega t} \iint_{S} \frac{v_{0}}{2 \pi} \frac{e^{-j k r_{A}}}{r_{A}} \mathrm{~d} s,
$$

where $r_{A}$ represents the distance between a knowledge element of the circular knowledge radiator and the point $M$ in the knowledge field at which the knowledge receiving enterprise is located. $S$ denotes the circular face of the knowledge radiator of radius $a$. The knowledge receiving enterprise is located at a point $z$ on the axis, where $r_{A}=\sqrt{z^{2}+\rho^{2}}$.

From formula (2), knowledge reduction magnitude function can be obtained after simplification:

$$
p_{m}(r)=\left|\sin \left[\frac{k}{2}\left(\sqrt{z^{2}+a^{2}}-z\right)\right]\right| .
$$

The influence on knowledge transfer within the knowledge field is equivalent to the knowledge waves. With a continuous cyclical variation over time, the influence amplitude $P_{m}(r)$ represents the distribution of the knowledge transfer influence of the circular knowledge radiator on the knowledge receiving enterprises as a function of the relationship distance.

This function shows that the distribution function $p_{m}$ describing the knowledge transfer influence amplitude is related to the knowledge wave number $k$, the radius $a$ of the circular knowledge radiator, and the relationship distance $z$ between the knowledge sending enterprise and the knowledge receiving enterprise.

The relationship distance reflects the relationship state of knowledge transfer subject in the process of knowledge transfer, and the relationship distance from near to far represents the state of knowledge transfer subject from intimacy to alienation. Although the relationship distance reflects a kind of gradual change, this paper uses the phased description method in the description.

When the relationship distance is close in the process of knowledge transfer, this paper holds the opinion that the subject of knowledge transfer adopts a relatively intimate transfer method, such as face-to-face teaching, commissioned research, and consultation, which is called intimate knowledge transfer. When the relationship distance is moderate in the process of knowledge transfer, this paper holds the opinion that the subject of knowledge transfer adopts a relatively stable but not very intimate transfer method, such as knowledge transfer through the Internet, personnel

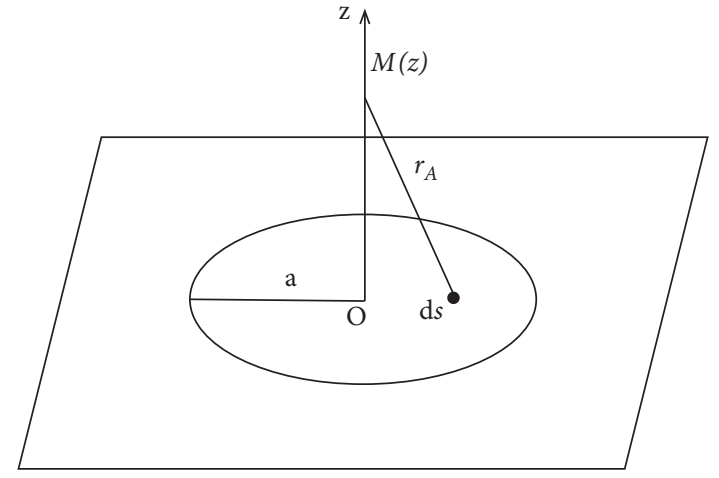

FIgURE 4: Coordinate frame for the circular knowledge radiator model.

exchanges, professional meetings, and the establishment of research centres, which is called stable and moderate intimate knowledge transfer. When the relationship distance is far away from each other in the process of knowledge transfer, this paper holds the opinion that the degree of connection between knowledge transfer subjects is very poor. Knowledge exchange between enterprises is rare, and it is generally difficult to achieve a good knowledge transfer effect.

The knowledge wave number and knowledge wave transfer frequency can be replaced by constants (see the appendix for details). The knowledge wave number reflects the speed at which the knowledge alliance transmits knowledge waves, that is, the amount of knowledge transferred per unit time. The faster the alliance delivers knowledge, the greater the knowledge wave number. In order to facilitate discussion and understanding, in the following discussion, knowledge transfer frequency will be used to reflect the change in knowledge wave number. The radius of the circular knowledge radiator reflects the number of knowledge subjects participating in knowledge transfer in the knowledge alliance. The larger the volume of knowledge involved in knowledge transfer is, the larger the radius of the circular knowledge radiator is. Under normal circumstances, the volume of knowledge involved in knowledge transfer has a positive linear relationship with the number of knowledge sending enterprises participating in knowledge transfer. As the number of enterprises in a knowledge alliance increases, the volume of available knowledge increases. Because the knowledge volume is difficult to quantify, this paper uses the number of enterprises in the knowledge alliance instead of the knowledge volume for model construction. Different enterprises have different understanding of the same knowledge. In the process of knowledge transfer within knowledge alliance, the overlapping knowledge of all members constitutes the knowledge understanding of the alliance. The more the members the alliance have, the greater the "broadness" of knowledge will be involved in knowledge transfer.

\section{Simulation Analysis}

Matlab programming was used to implement the function describing the relationship between the knowledge transfer 
effect of the circular knowledge radiator and the relationship distance between enterprises and to carry out a corresponding simulation analysis.

3.1. Discussion of Variable Relationships. By analysing three different situations regarding the number of enterprises participating in the knowledge alliance and the frequency of knowledge transfer, the knowledge transfer process at different relationship distances will be investigated here to characterize the relationship between relationship distance and knowledge influence. For the simulations, the dimensions of the knowledge transfer frequency and the number of knowledge alliance enterprises are set to 1 to facilitate parameter setting.

To facilitate the discovery of the inherent laws relating the number of enterprises participating in the knowledge alliance, the frequency of knowledge transfer, and the distance of the relationships between the enterprises, a general knowledge alliance situation is first analysed. To represent a case in which the knowledge alliance is moderately sized and the knowledge transfer ability is also at a moderate level, the parameters are set to $k=4$ and $a=5$, and the corresponding influence amplitude distribution map on the knowledge radiator axis is shown in Figure 5.

As shown in Figure $5, D_{0}$ divides the graph into a region that shows irregular undulations and a region that shows a monotonic decrease in the knowledge influence amplitude with increasing distance. $D_{0}$ is the point at which the influence amplitude reaches its maximum value at the farthest distance from the knowledge source. In acoustic theory, the corresponding distance is called the "Rayleigh distance", which is regarded as the threshold between the far sound field and the near sound field. We therefore introduce a similar concept into the proposed model of knowledge transfer in a knowledge alliance, and we call this distance the knowledge Rayleigh distance.

Based on the observed distribution pattern of the knowledge Rayleigh distance $D_{0}$, the influence amplitude shows oscillations along the $z$ axis in the region of $z<D_{0}$. This phenomenon occurs because the circular knowledge radiator of the knowledge alliance is composed of a number of enterprises that can transfer different levels of knowledge. If the relationship between the knowledge source and the knowledge receiver is too close, the noncore knowledge transferred by a noncore enterprise is more likely to be affected by other transmitted knowledge; consequently, this information is likely to be mixed with knowledge output unrelated to the current knowledge transfer, resulting in knowledge bias. Simultaneous noncore knowledge transfers will affect each other, preventing the accurate knowledge transmission and even causing distortion of knowledge. Thus, a relationship that is too tight can lead to uncontrollable and distorted knowledge transfer. In the region of $z>D_{0}$, the influence amplitude decreases monotonically with increasing relationship distance, indicating that, beyond a distance $D_{0}$, the mutual influence among different types of knowledge is weaker than the relationship with distance, making the relationship distance influence dominantly on the effect of knowledge transfer. Figure 5 shows that $D_{0}$ is an extreme point, the slopes of the curve before and after the point $D_{0}$ are very small, and the distribution curve is very smooth. These observations indicate that the knowledge alliance has a great influence on knowledge receiving enterprises in the vicinity of $D_{0}$, the mutual influence of knowledge transfer among enterprises is small, and within a certain range, the knowledge influence changes little with the relationship distance. Therefore, the vicinity of $D_{0}$ is a relatively controllable area with a good knowledge transfer effect. Consequently, determining the distance $D_{0}$ is of great significance for research on knowledge transfer in the knowledge alliance. In the region of $z>D_{0}$, the influence amplitude decreases following a law of the form $\propto 1 / z$. This effect occurs because when the relationship is very distant, the mutual influence of knowledge transfer between enterprises is small enough to be negligible. Hence, the influence amplitude is affected only by the relationship distance. The entire knowledge field can be divided into a near field and a far field, distinguished by the distance $D_{0}$. The region of $z<D_{0}$ is called the near field of the knowledge source, and the region of $z>D_{0}$ is called the far field of the knowledge source.

Now, let us analyse the relationship between relationship distance and knowledge influence when the number of enterprises in the knowledge alliance is very small and the frequency of knowledge transfer is low. The relevant parameters are set to $k=1$ and $a=1$. The corresponding amplitude distribution representing the influence on the axis of the knowledge radiator is shown in Figure 6.

When the number of enterprises in the knowledge alliance is small, the amount of knowledge involved in the transfer is also small, the knowledge transfer speed is extremely slow, and the amount of knowledge that can be transferred simultaneously is naturally small. Figure 6 shows that, in this case, the curve of the knowledge influence amplitude monotonically decreases with increasing relationship distance, following a nearly $\propto 1 / z^{2}$ law. That is, at small relationship distances, the knowledge influence rapidly weakens as the relationship distance increases.

Figure 6 shows that the magnitude of the knowledge influence decreases with increasing distance from a distance of 0 . When the relationship distance is 20 , the magnitude of the knowledge influence is reduced to $5 \%$ of its peak value. This result arises because the number of enterprises in the knowledge alliance is too small, and the knowledge transfer process can be seen as a peer-to-peer process. Since the amount of knowledge available for transfer is too small, there is almost no influence from noncore knowledge, and naturally, there is no biasing or distortion of knowledge. The magnitude of the knowledge influence is affected by only one factor, namely, the relationship distance. However, because of the lack of relevant knowledge, a single instance of knowledge transfer is greatly affected by the relationship distance. When the relationship is not sufficiently close, the knowledge transfer effect will be greatly reduced. 


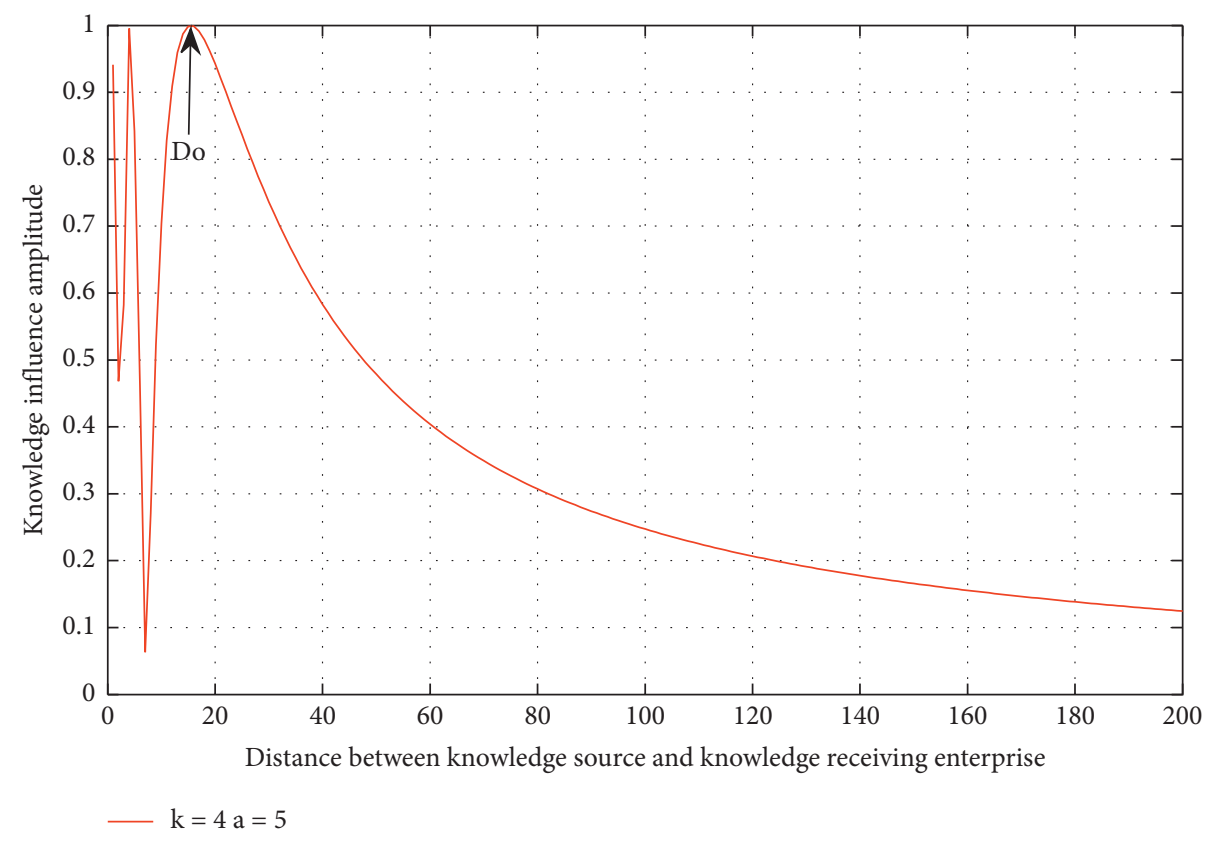

FIGURE 5: Distribution of knowledge influence intensity in the knowledge field.

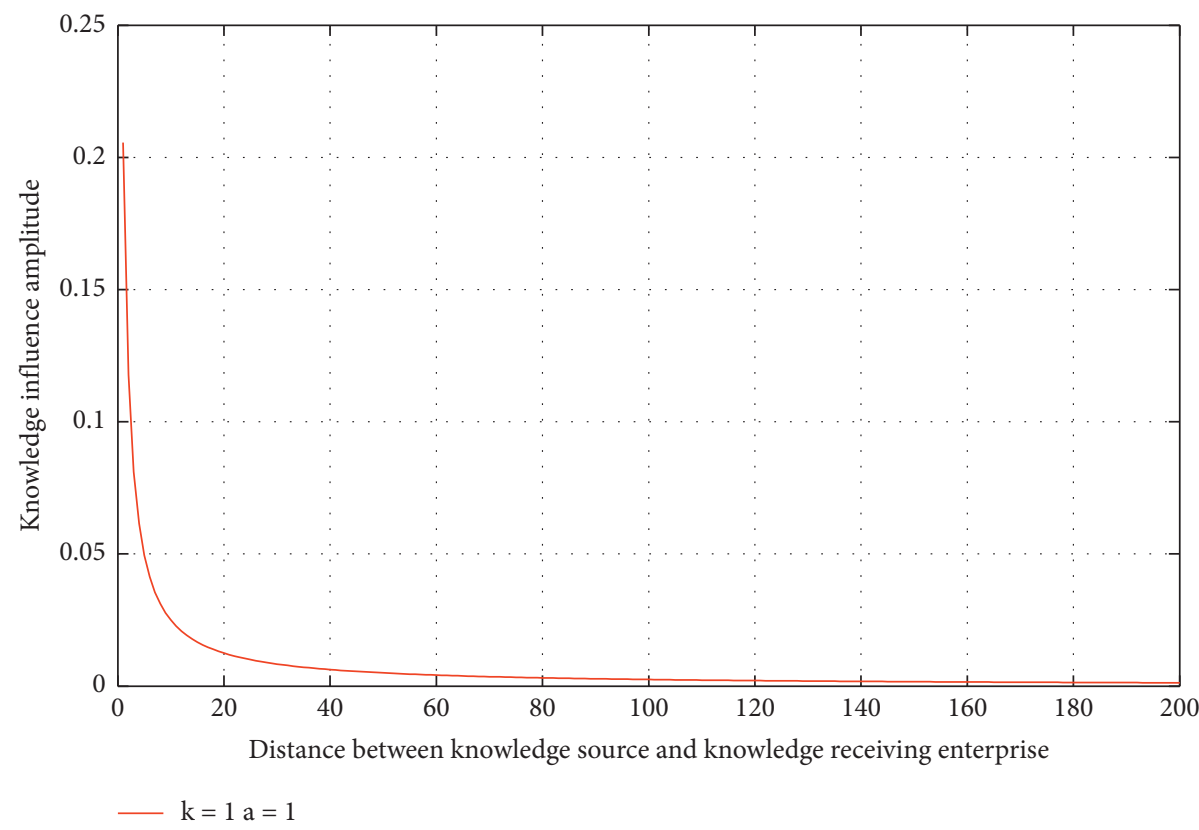

Figure 6: Distribution of the influence in the knowledge field when the alliance is small and the transfer frequency is very low.

Finally, the relationship between relationship distance and knowledge influence is analysed for a case in which the knowledge alliance is large and the relevant knowledge transfer efficiency is high. The relevant parameters are set to $k=10$ and $a=10$. The influence amplitude distribution on the axis of the knowledge radiator can be obtained, as shown in Figure 7.

When the knowledge alliance is large and the knowledge transfer frequency is high, the number of enterprises participating in the alliance is relatively large, the knowledge volume is also large, and the knowledge transfer is greater. In this case, the knowledge transfer capabilities of the knowledge alliances are strong, and the interaction with noncore knowledge is consequently exacerbated. Figure 7 shows that there are many oscillations in the curve in the region of $z<D_{0}$. These oscillations occur because the knowledge transfer among the enterprises in the knowledge alliance becomes relatively strong as the speed with which knowledge waves are emitted by the circular knowledge radiator becomes faster and the volume of knowledge increases. Consequently, a greater degree of interaction will occur in this situation. Compared to the general situation, 


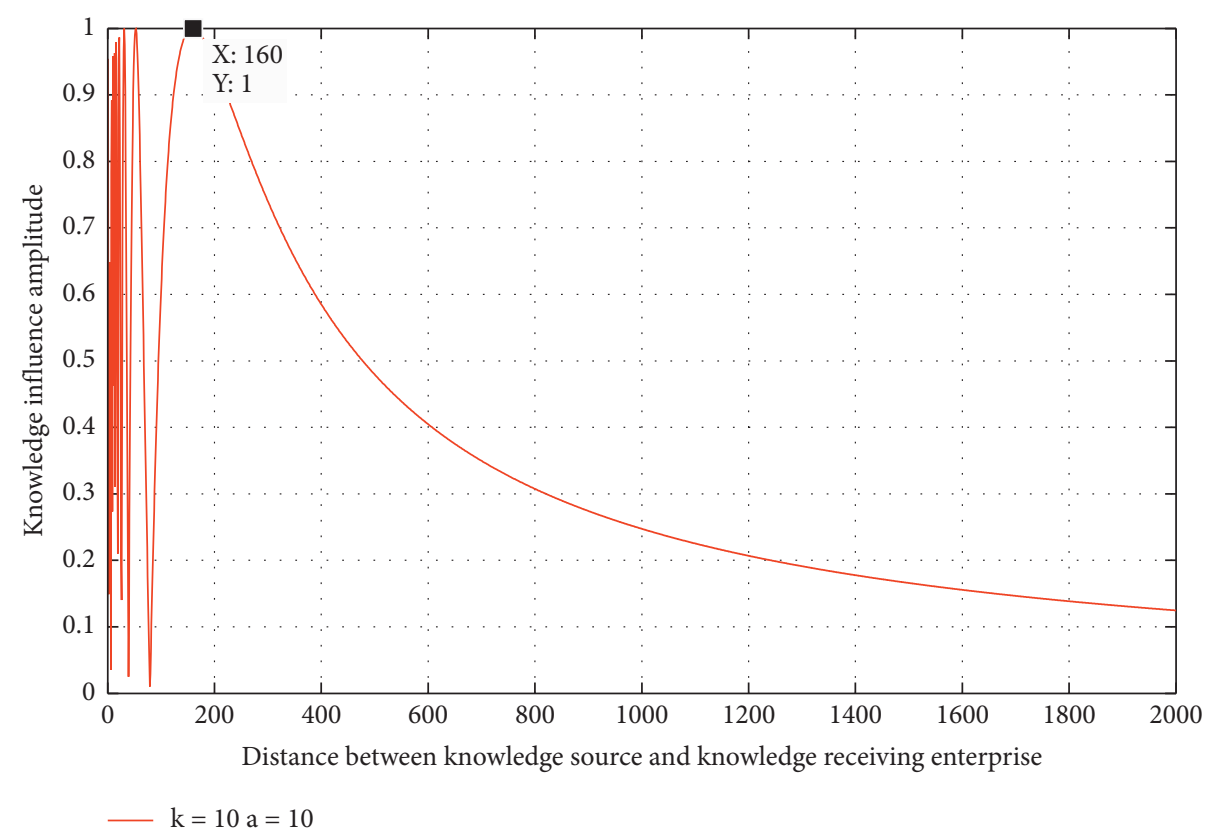

Figure 7: Distribution of the influence amplitude in the knowledge field when the alliance is large and the transfer efficiency is high.

because of the increased intensity of the knowledge transfer process, the interaction effect is more complicated and unstable, and there are more uncertain factors involved. In addition, Figure 7 shows that the Rayleigh distance $D_{0}$ is 160 , which is much larger than usual. That is, in this case, the farfield region of the knowledge field corresponds to a farther distance, indicating that an increase in $k$ and $a$ has a positive effect on the Rayleigh distance $D_{0}$. This finding can be attributed to the increase in the amount of knowledge available and the increase in the number of enterprises involved in knowledge transfer, which cause the knowledge transfer process to be more stable and less affected by related factors. The figure shows that the distribution curve decreases more slowly in the far-field region of the knowledge field, with both the slope and the rate of change of the slope being smaller.

This paper discusses the knowledge transfer performance of knowledge alliances when the number of enterprises and the frequency of knowledge transmission are moderate, low, and high. We find that the vicinity of the knowledge Rayleigh distance is a region with a good knowledge transfer effect and that the knowledge field can be divided into a near-field region and a far-field region based on the knowledge Rayleigh distance. The knowledge transfer process follows different rules in the near field and the far field. Knowledge transfer to the knowledge receiving enterprises in the near field is very unstable, whereas the knowledge influence in the far field is monotonically attenuated as the relationship distance increases. From a comparison of the three cases, it can be seen that when the number of enterprises and the frequency of knowledge transmission are greater, the knowledge Rayleigh distance is larger, and the influence of the knowledge alliance on the knowledge transfer to knowledge receiving enterprises varies more slowly in the far field.
3.2. Further Discussion. In the previous section, we discussed three kinds of conventional knowledge alliances for which the number of enterprises and the frequency of knowledge transmission are moderate, low, and high and found that these alliances show different knowledge influence trends at different distances. Next, we will further discuss the impact of these two indicators (number of enterprises and frequency of knowledge transfer) on the knowledge transfer by evaluating the impact of changes in either $k$ or $a$ when the value of the other indicator is fixed.

The results for $k=1$ and $a=2,5,10,20$ are shown in Figures $8(\mathrm{a})-8(\mathrm{~d})$. The results for $a=1$ and $k=2,5,10,20$ are shown in Figures $9(\mathrm{a})-9(\mathrm{~d})$. From a comparison of Figures 8 and 9 , it can be seen that $k$ and $a$ have similar effects on knowledge transfer. When the $k$ value or the $a$ value remains unchanged, as the value of the other parameter increases, the knowledge Rayleigh distance of the knowledge influence amplitude curve also increases, and the near field of the knowledge field shows more oscillations. Additionally, the attenuation with distance of the knowledge influence amplitude in the far field becomes slower.

In other words, when the frequency of knowledge transfer becomes higher and the knowledge Rayleigh distance of knowledge transfer is larger, the knowledge alliance needs to maintain a more stable, relatively far relationship distance to ensure the best knowledge transfer effect. This is because when increasing frequency of knowledge transfer, the amount of knowledge transferred per unit time will increase. According to the theory of strong ties and weak ties, if the knowledge transfer enterprises keep strong association with each other, external factors will disturb the process of knowledge transfer, which is easy to cause deviation in knowledge content in knowledge transfer. Keeping weak association can produce better knowledge transfer effect. 


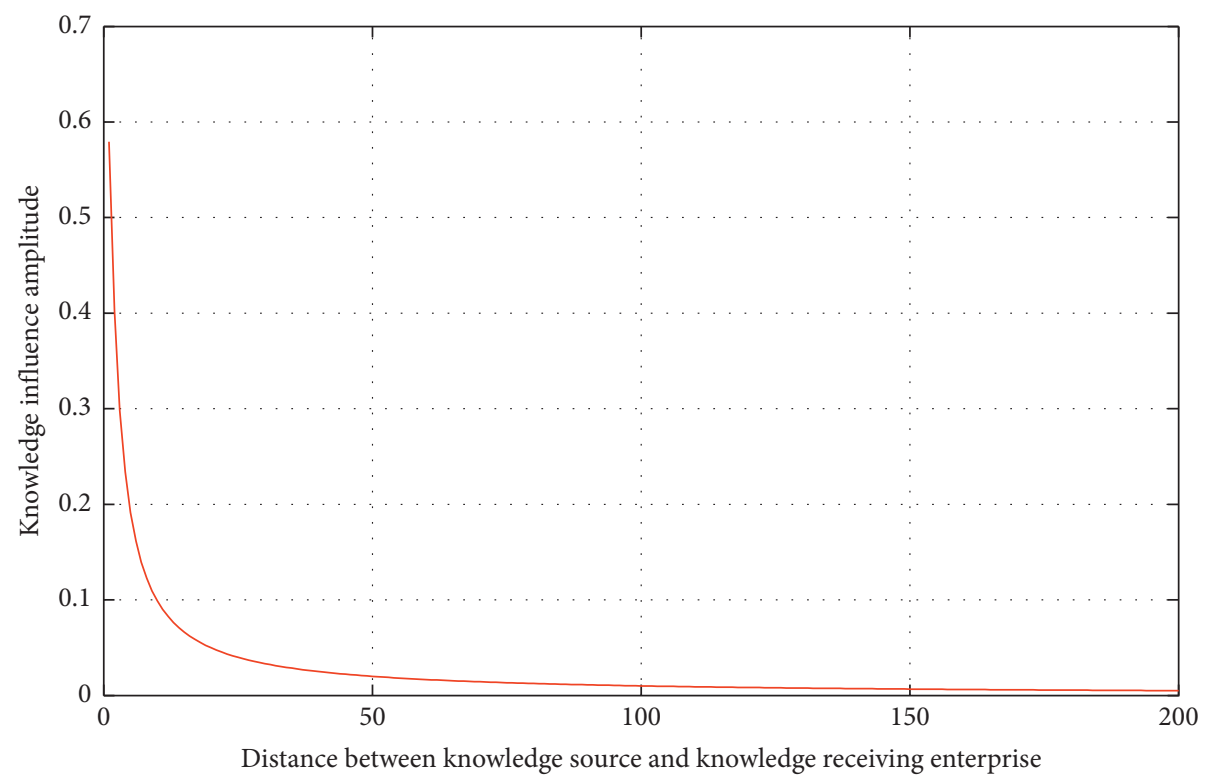

$\ldots \mathrm{k}=1 \mathrm{a}=2$

(a)

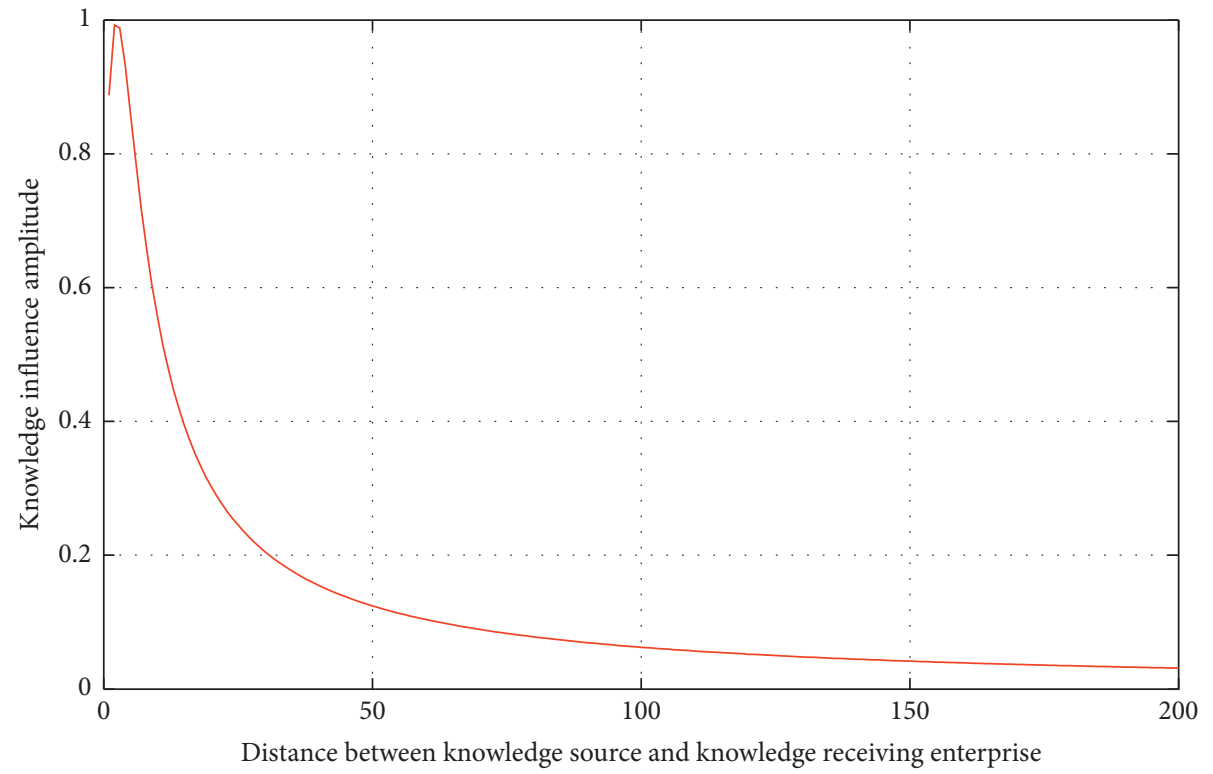

(b)

Figure 8: Continued. 


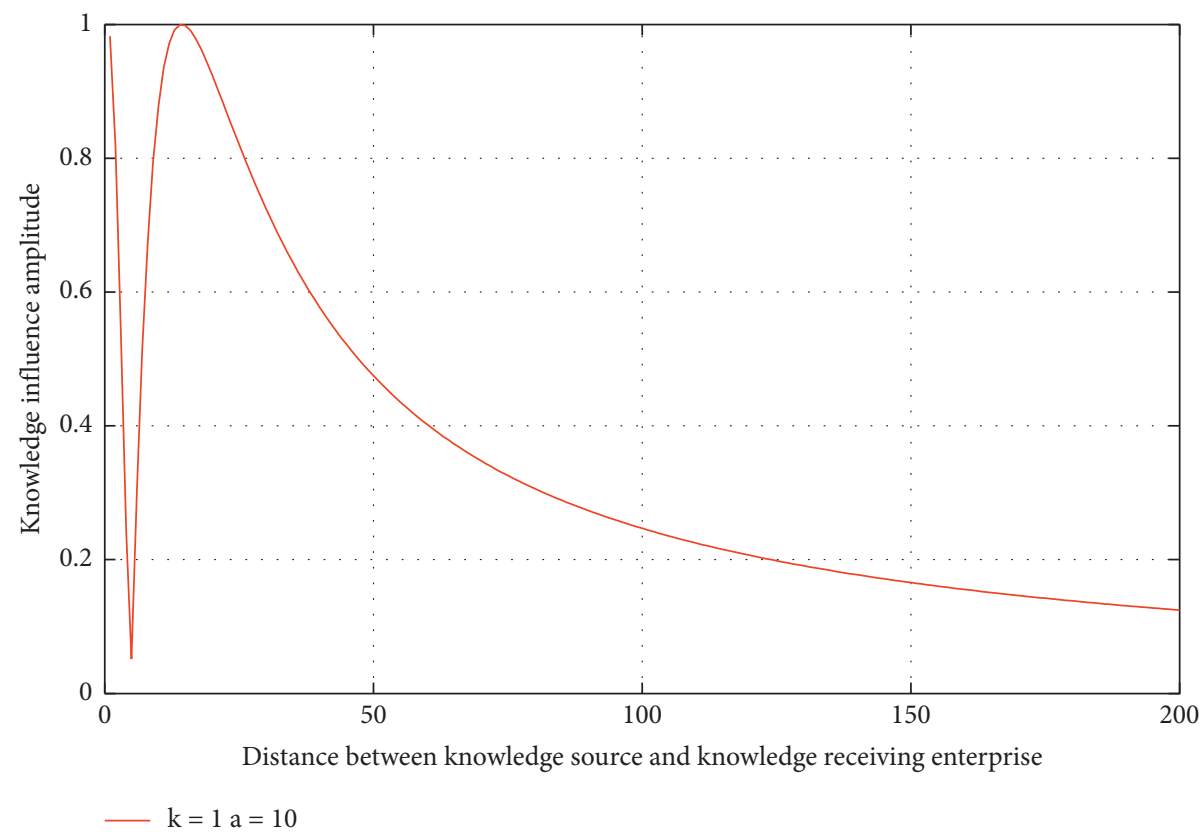

(c)

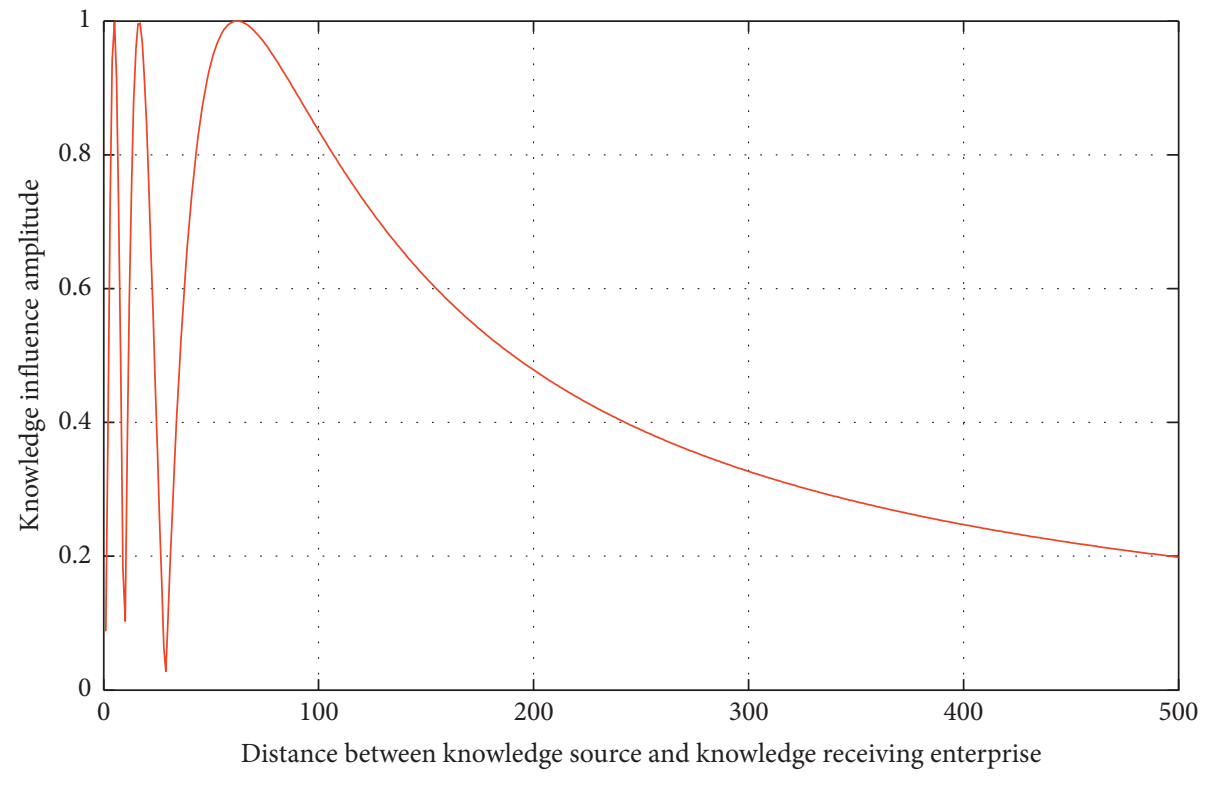

(d)

FIGURE 8: Distributions of the influence amplitude in the knowledge field when $k=1$ and $a=2,5,10,20$. 


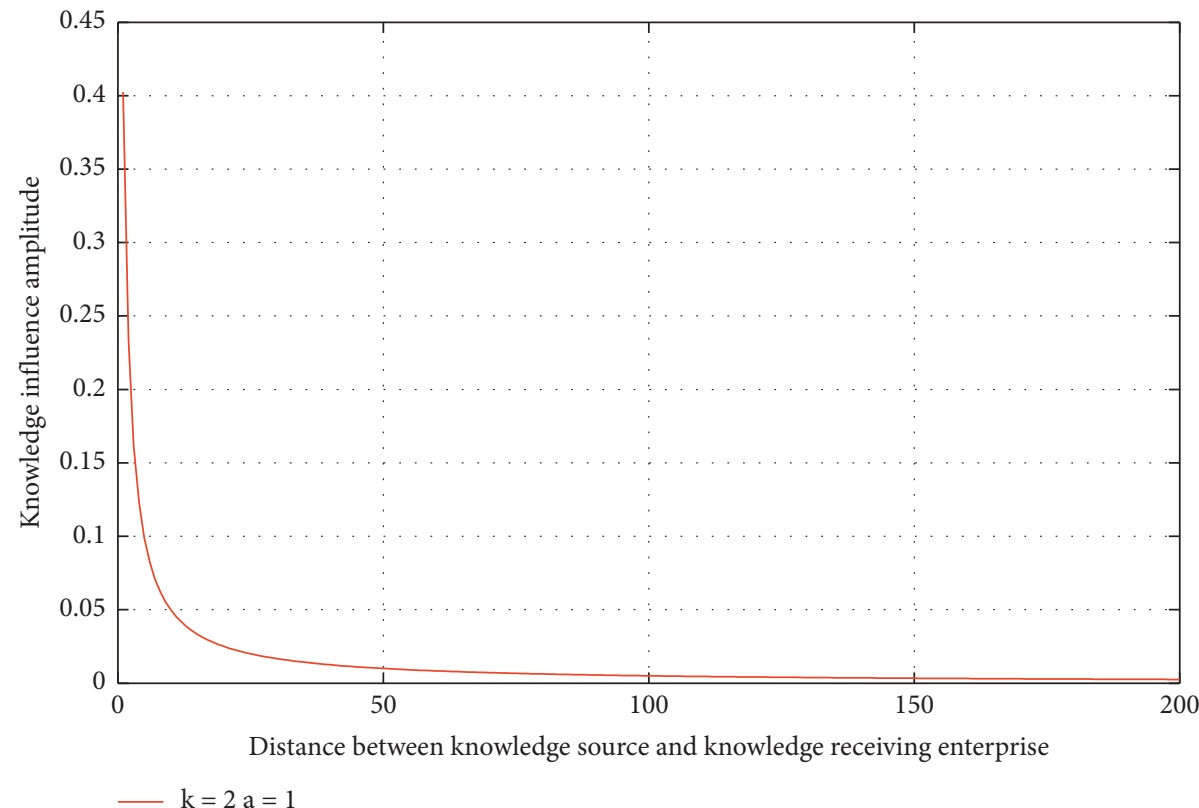

(a)

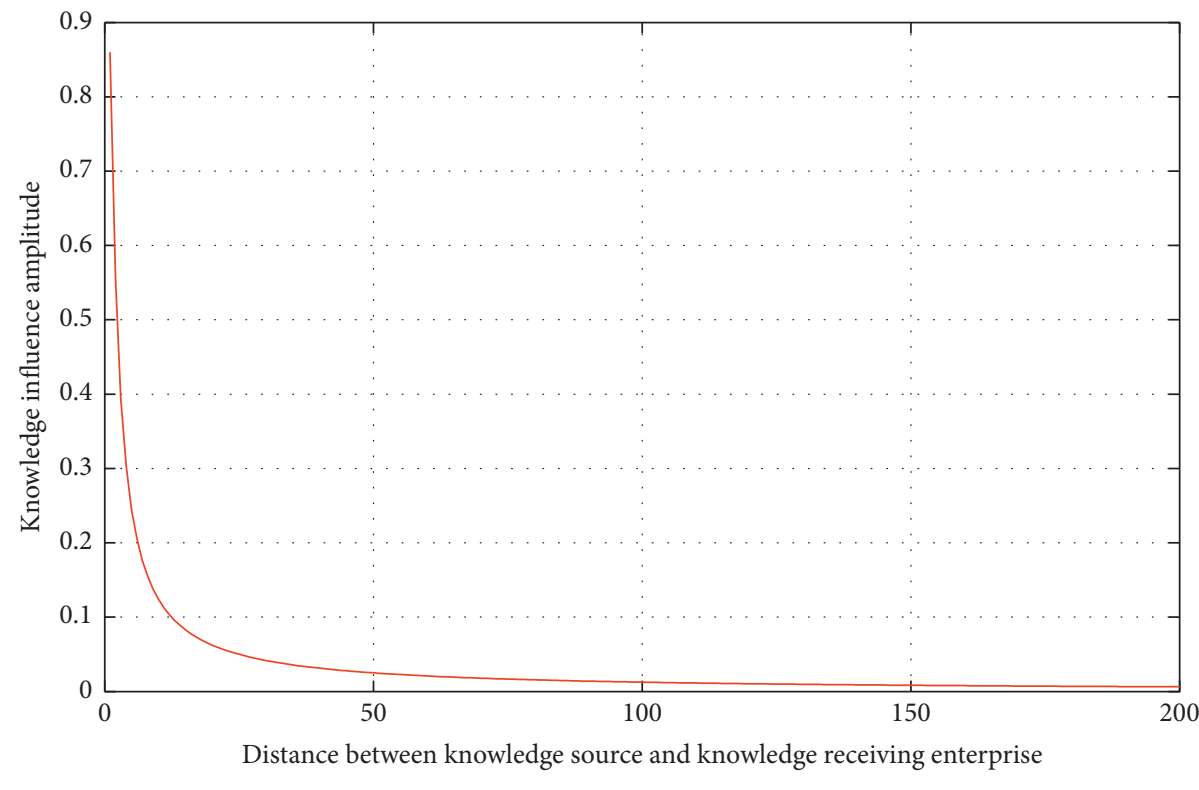

k $=5 \mathrm{a}=1$

(b)

Figure 9: Continued. 


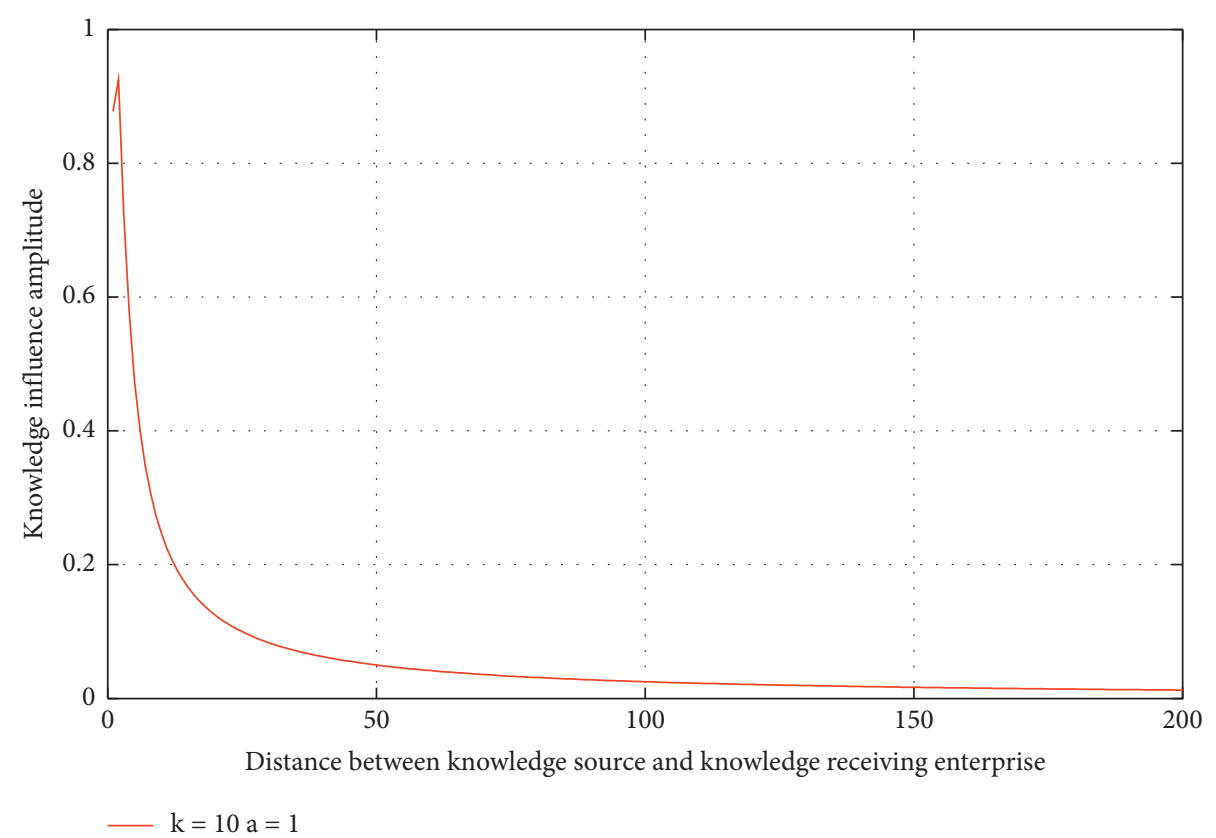

(c)

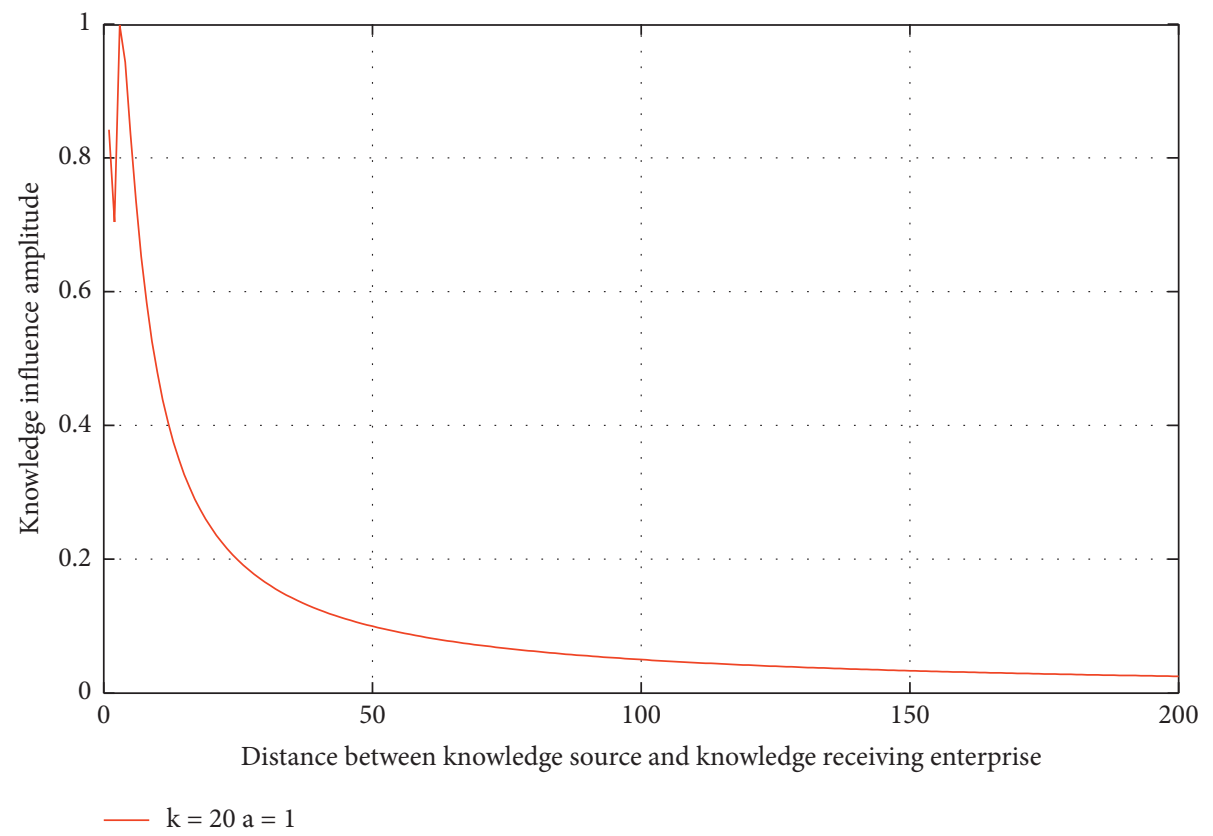

(d)

Figure 9: Distributions of the influence amplitude in the knowledge field when $a=1$ and $k=2,5,10,20$.

When the number of enterprises in the knowledge alliance increases, the knowledge alliance needs to be stable, and a relatively far relationship distance can produce good knowledge transfer effect. This is because in the process of knowledge transfer, the larger the number of enterprises in the alliance, the more the level of knowledge will be. Receiving enterprises can deepen their understanding of knowledge by receiving different levels of knowledge, but they are also vulnerable to multi-level knowledge. When there are many members in the alliance, the knowledge receiving enterprise should keep a certain relationship distance with the knowledge sending enterprise. If the relationship distance is too close, knowledge will be accepted without hesitation, which may lead to the deviation and distortion of understanding due to the multilevel understanding of knowledge in the alliance. Only by keeping a certain distance and selectively accepting and integrating the received knowledge, can enterprises understand and absorb the multilevel knowledge objectively.

This is consistent with the view of knowledge network and technology innovation network. According to the knowledge network theory, the organizational scale of 


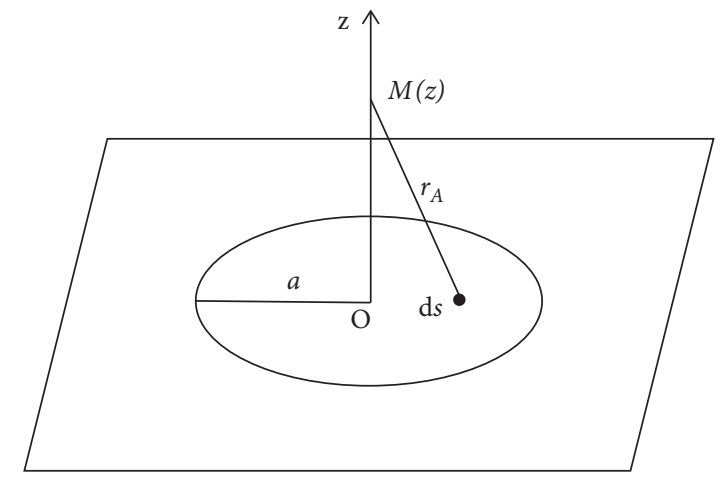

FIGURE 10: Coordinate frame for the circular knowledge radiator model.

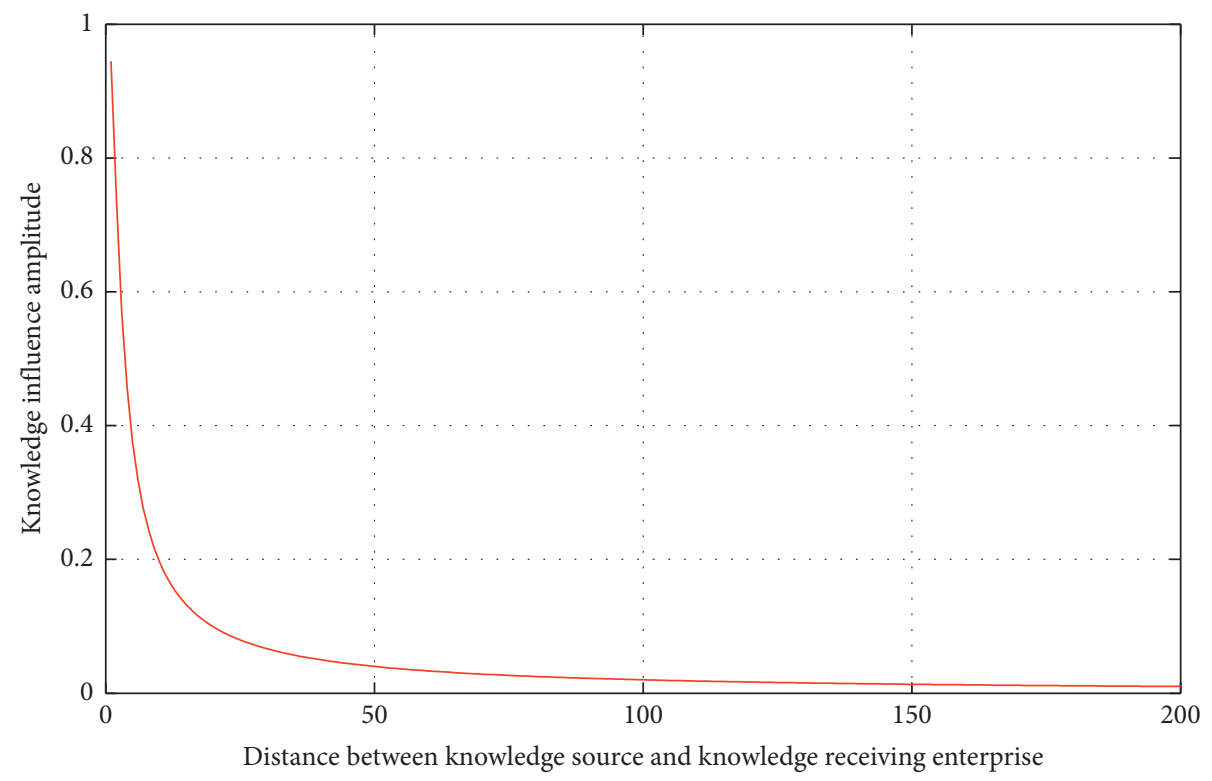

$-\mathrm{k}=2 \mathrm{a}=2$

(a)

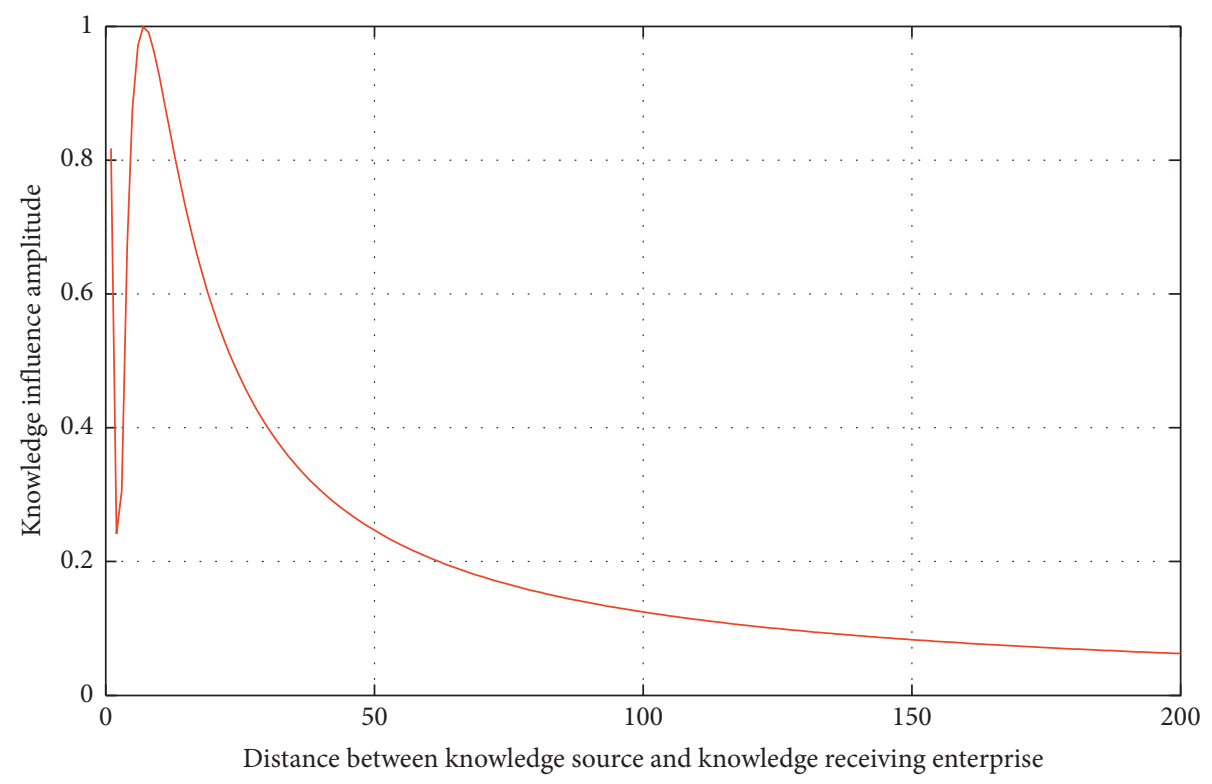

$\mathrm{k}=2 \mathrm{a}=5$

(b)

FIgURE 11: Continued. 


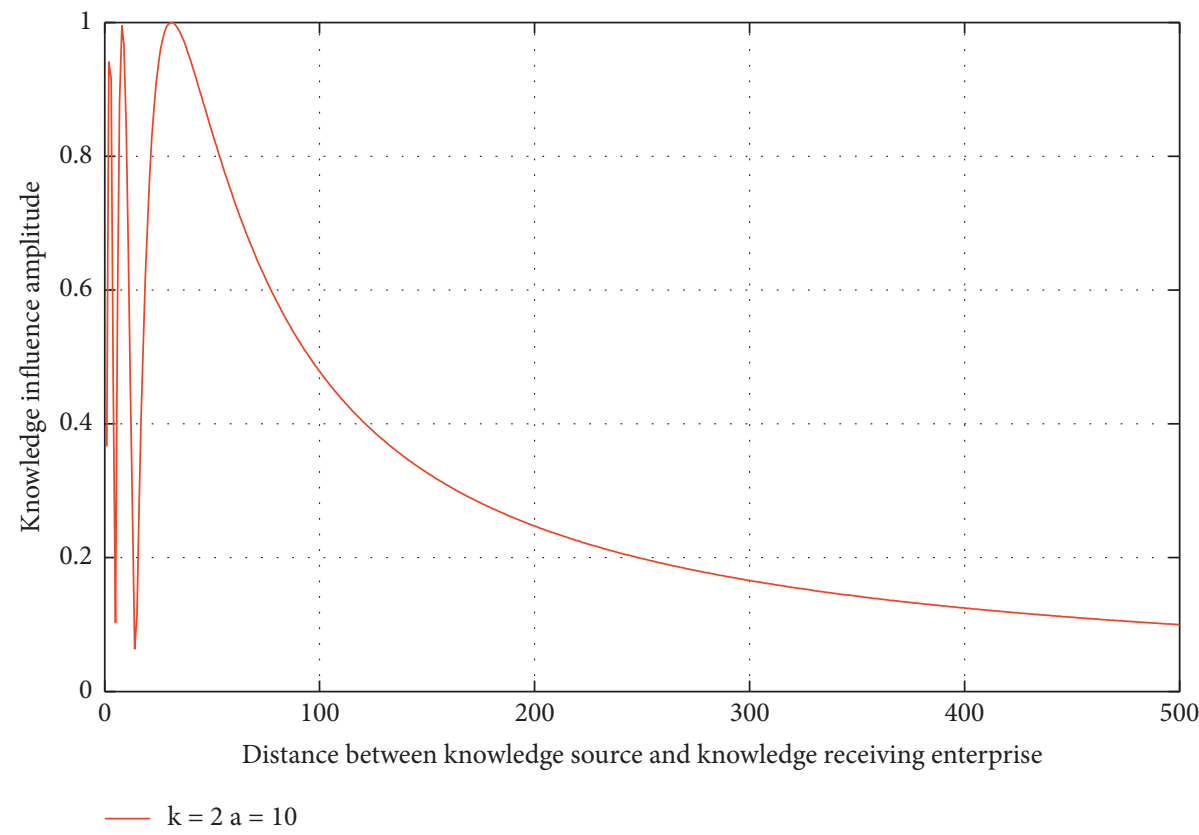

(c)

FIGURE 11: Distributions of the influence amplitude in the knowledge field when $k=2$ and $a=2,5,10$.

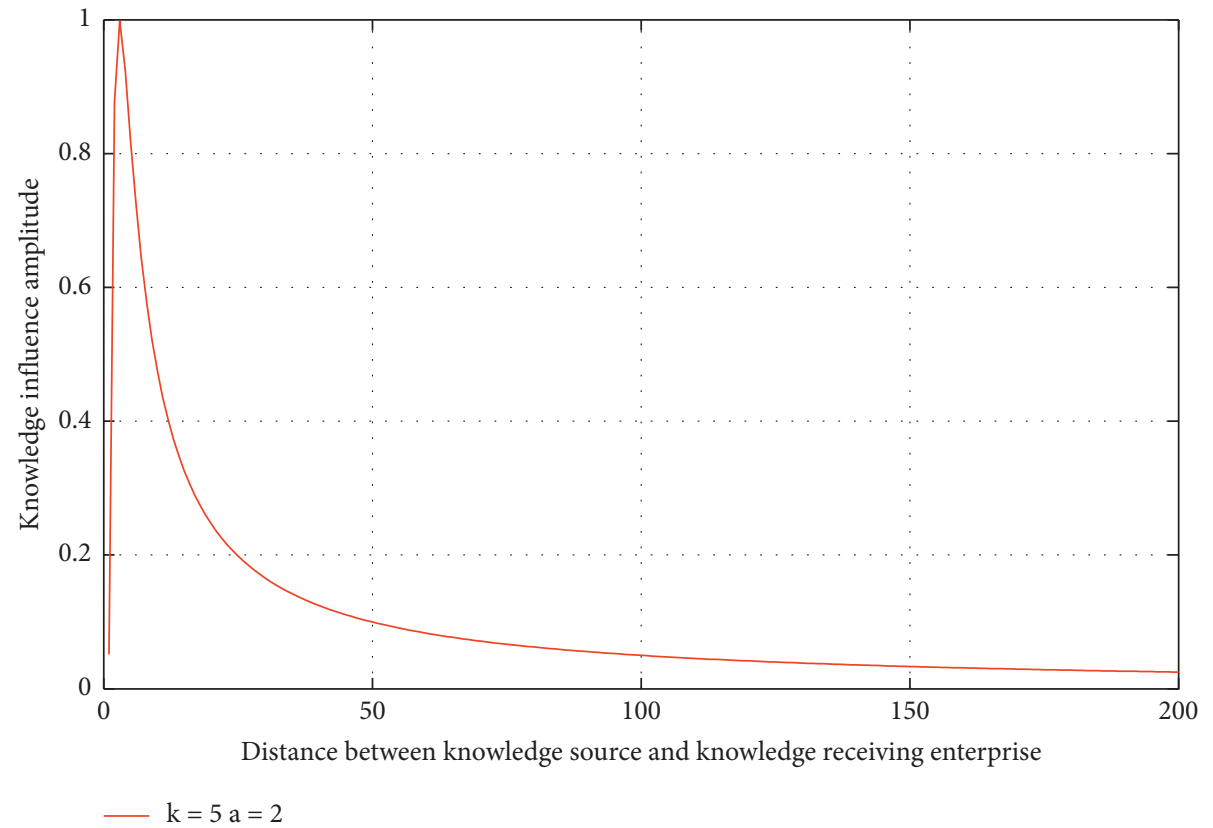

(a)

FIgURE 12: Continued. 


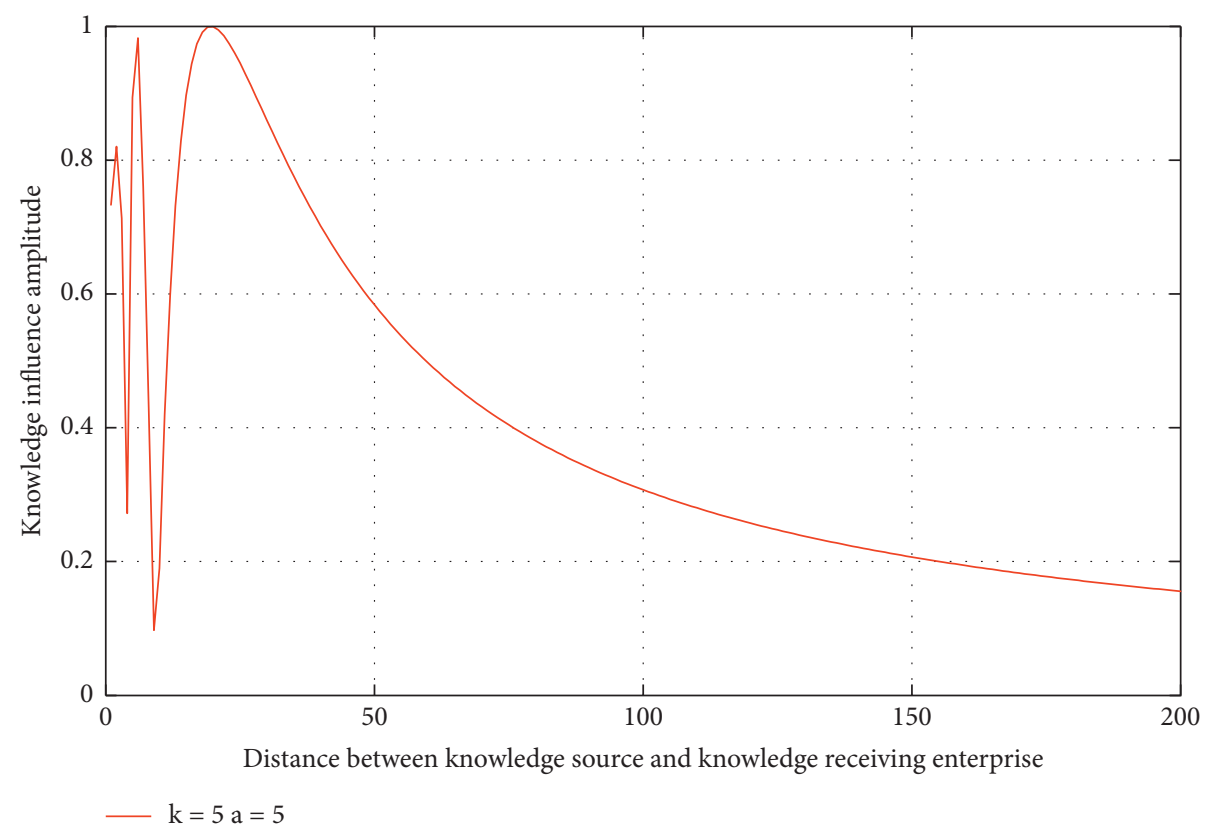

(b)

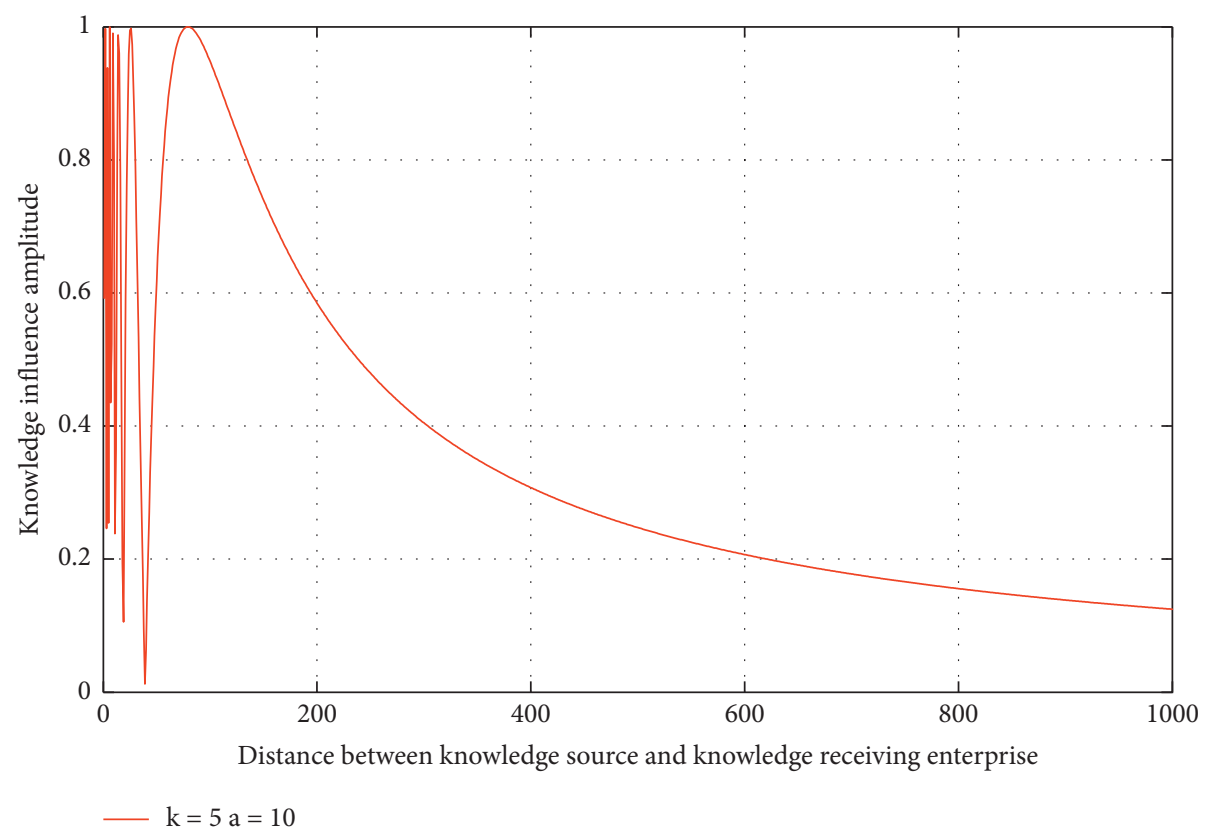

(c)

Figure 12: Distributions of the influence amplitude in the knowledge field when $k=5$ and $a=2,5,10$.

knowledge network can be regarded as the number of members in social network. There is a positive correlation between the number of enterprises in knowledge alliance and the complexity of the cooperation relationship among the members of knowledge alliance. The close relationship among enterprises will cause expensive communication costs, coordination costs, and supervision costs. According to the technological innovation network theory, maintaining a stable relationship within an organization helps to improve the efficiency of knowledge transfer and thus promote knowledge innovation. When the number of enterprises in knowledge alliance is large, it is difficult to maintain a stable intimate relationship, so it is better to keep the appropriate relationship distance when the organization scale is large.

This paper sets $k$ and $a$ to different values and continues to discuss the interactive relationship among the frequency of knowledge transfer, the number of knowledge alliance enterprises, and the relationship distance. Due to space limitations, this paper puts the specific discussion in the appendix.

This paper explores the specific impacts of these two influencing factors on knowledge transfer and the 


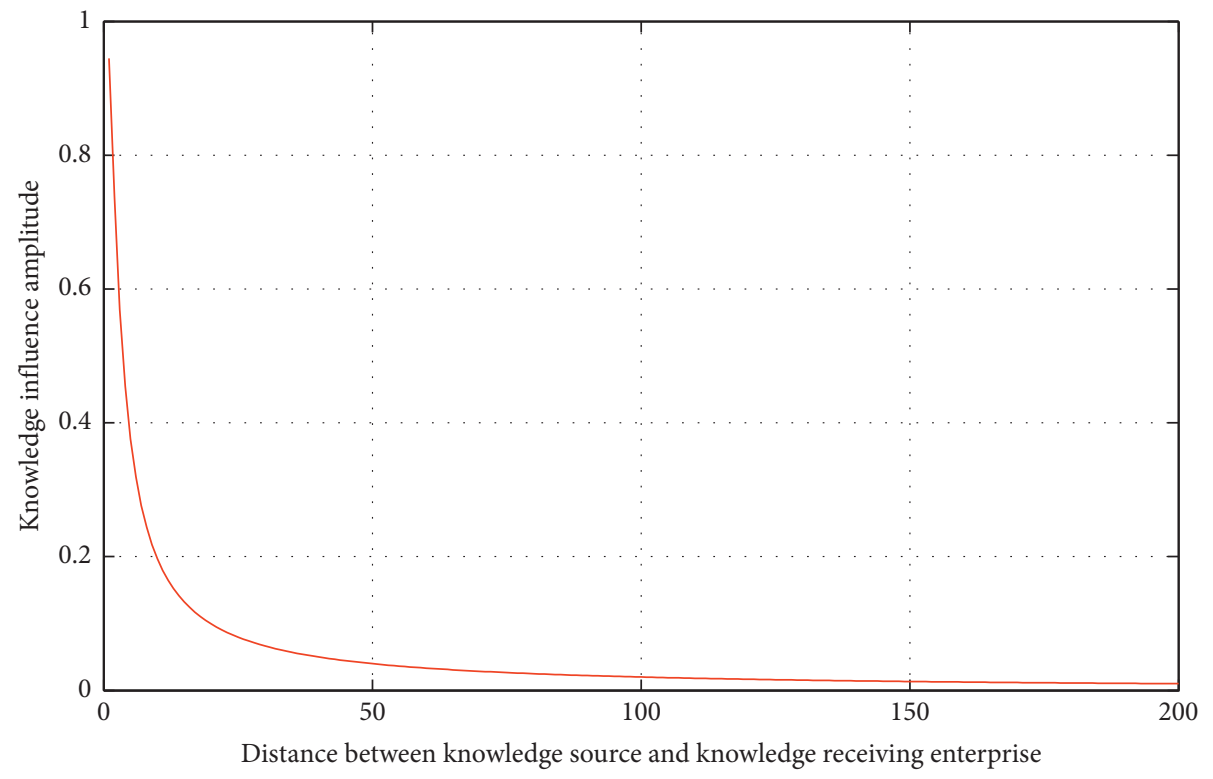

$-\mathrm{k}=2 \mathrm{a}=2$

(a)

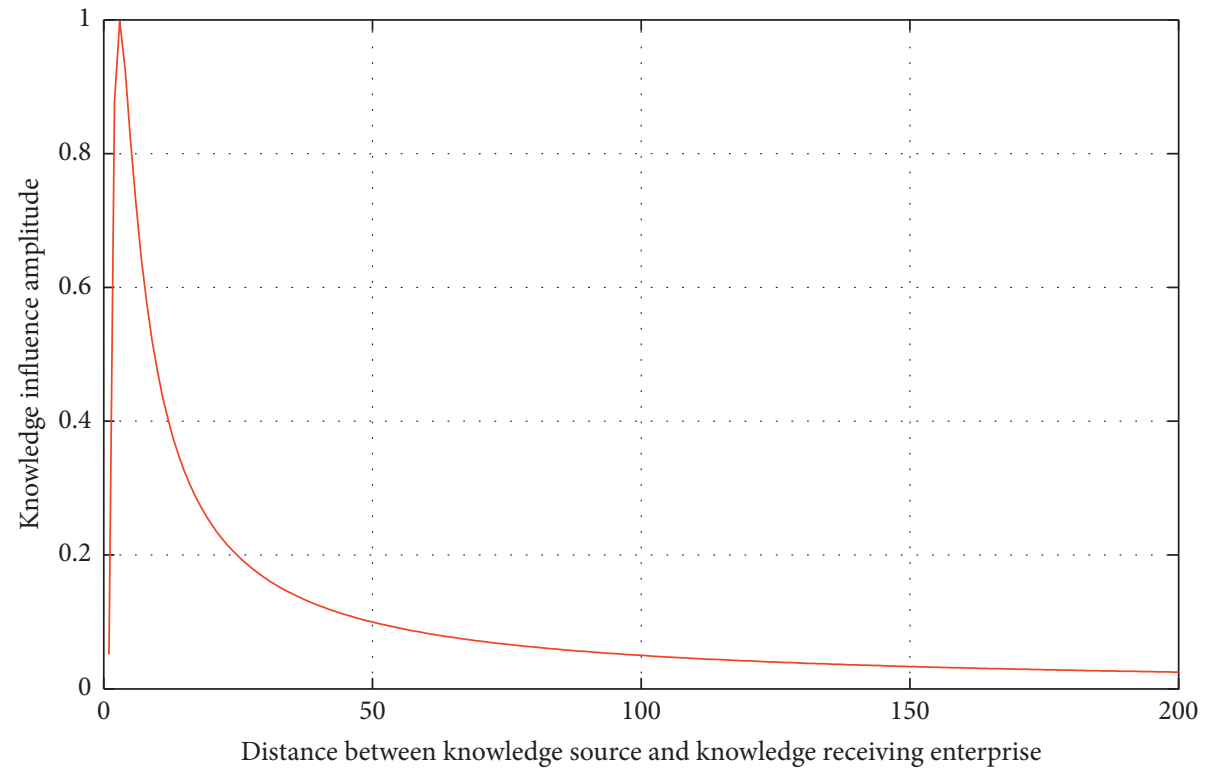

(b)

Figure 13: Continued. 


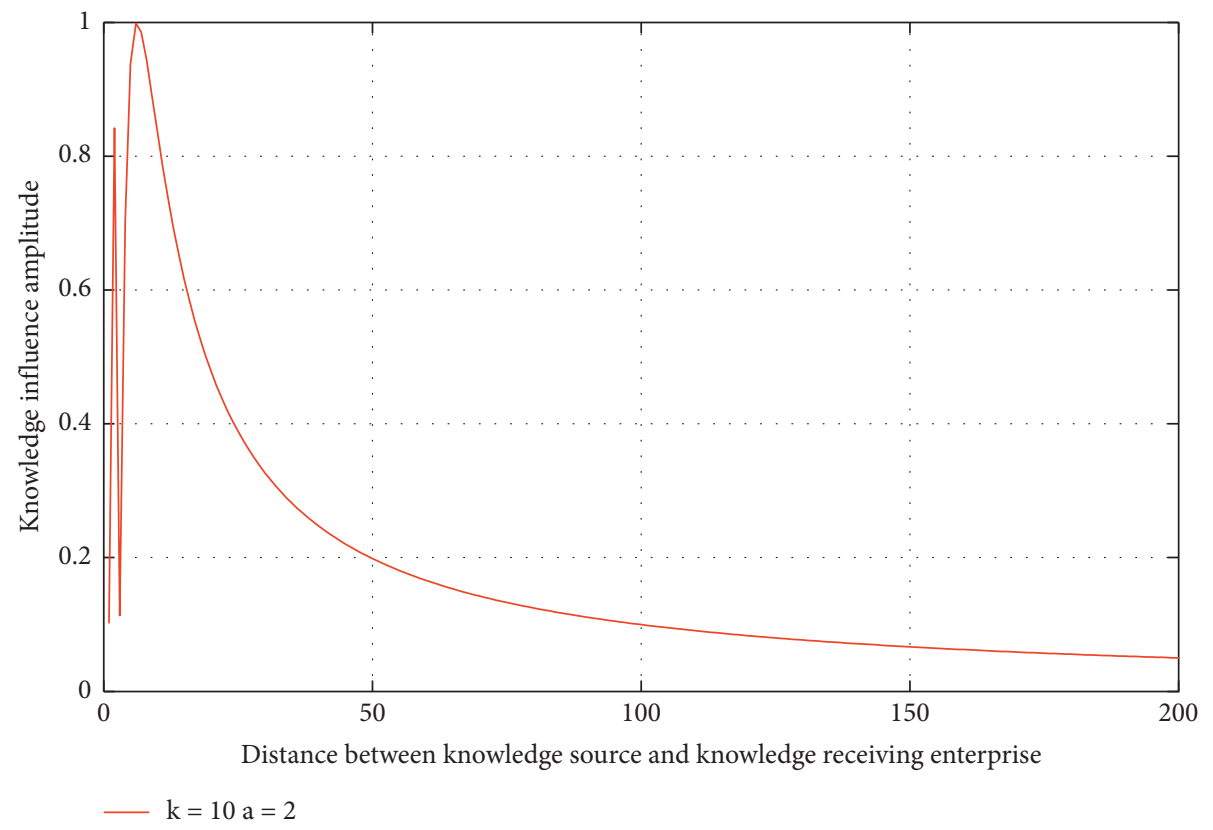

(c)

Figure 13: Distributions of the influence amplitude in the knowledge field when $a=2$ and $k=2,5,10$.

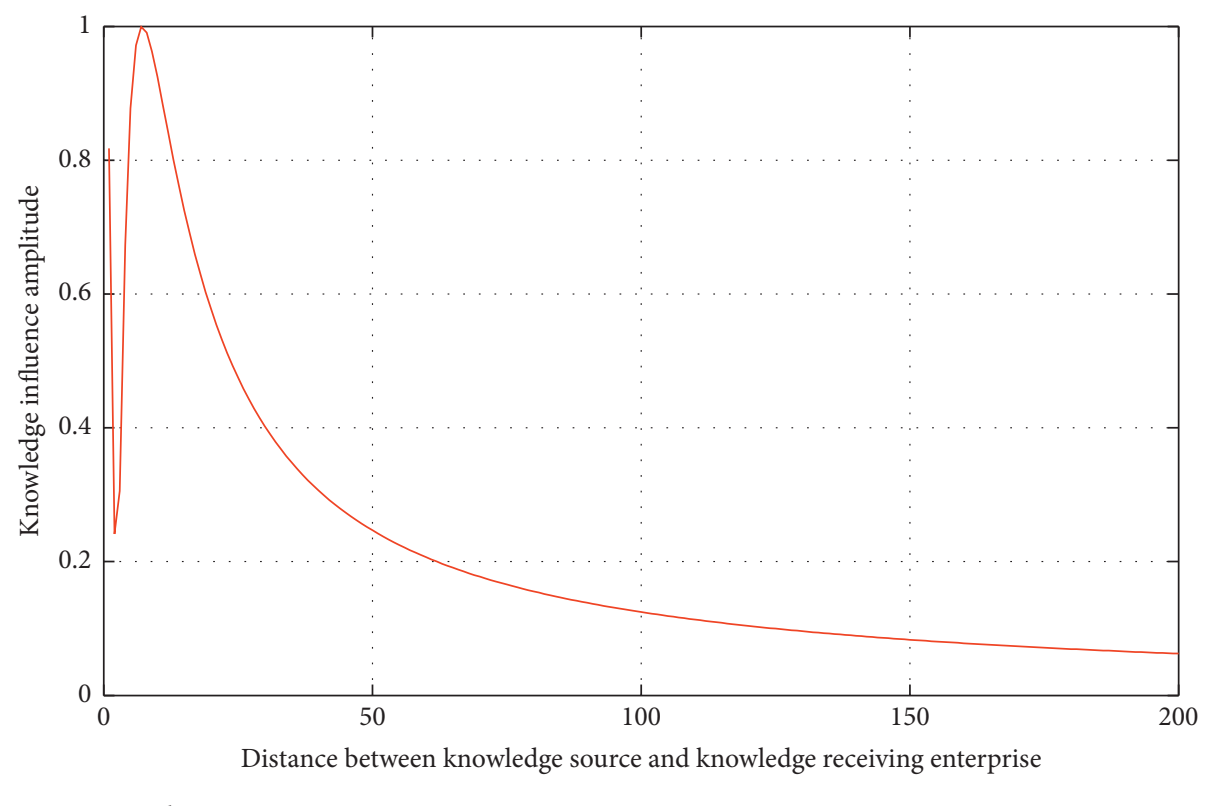

(a)

Figure 14: Continued. 


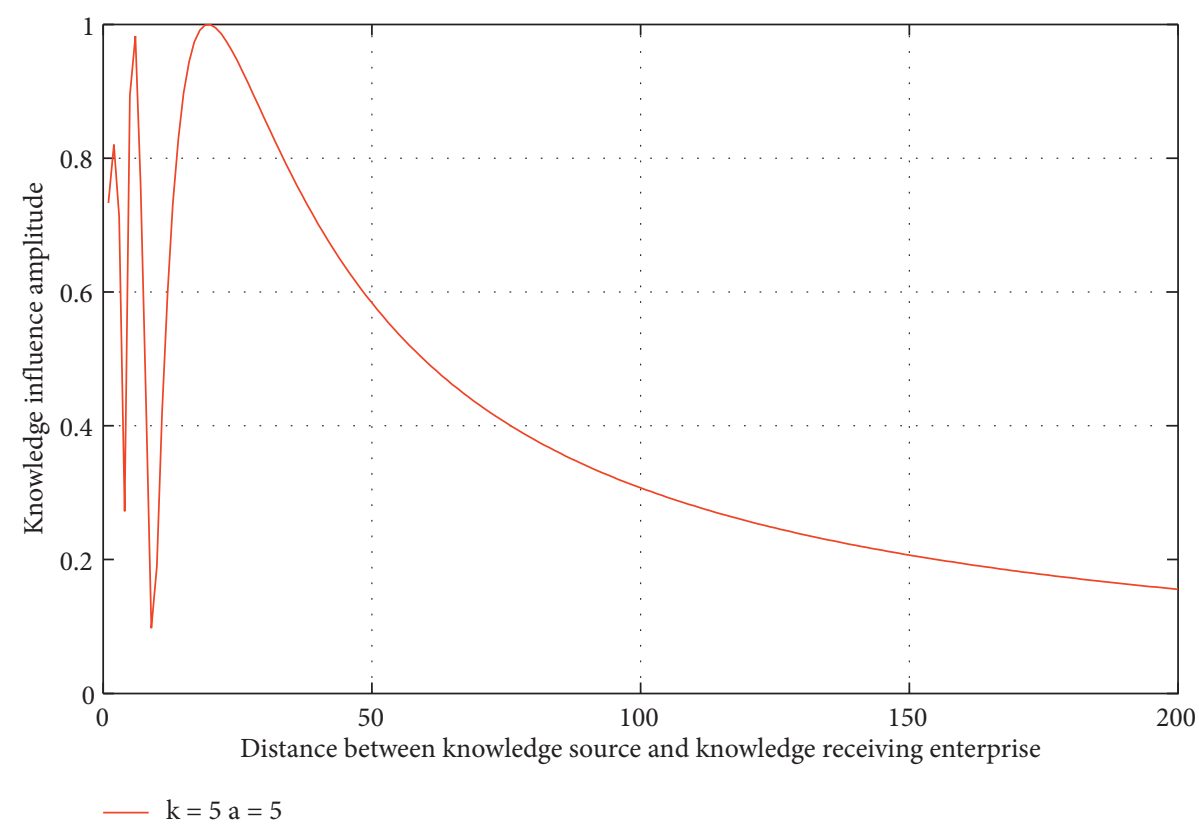

(b)

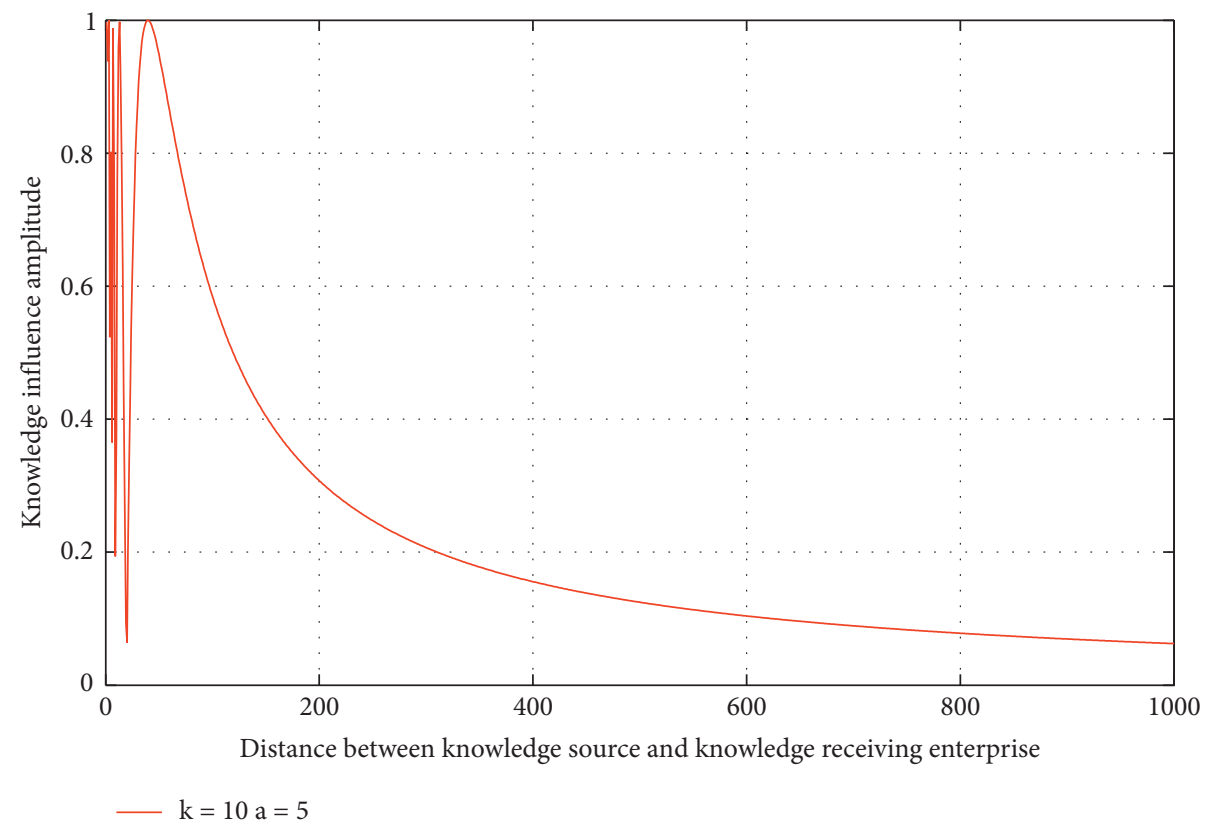

(c)

Figure 14: Distributions of the influence amplitude in the knowledge field when $a=5$ and $k=2,5,10$.

relationship between these two factors through an investigation of knowledge alliances with different numbers of participating enterprises and different frequencies of knowledge transfer. The number of enterprises and the frequency of knowledge transfer in a knowledge alliance are both important factors influencing knowledge transfer. The effects of these two influencing factors are similar. As the number of enterprises or the frequency of knowledge transfer increases, the instability of knowledge transfer in the near field increases. At the same time, the knowledge Rayleigh distance increases, and the rate of change in knowledge transfer in the far field slows down. These two influencing factors also mutually affect each other, with a change in one factor enhancing the effect of the other. However, the knowledge influence is more sensitive to changes in the number of enterprises, and correspondingly, the number of enterprises also exerts a more obvious effect on the influence of a change in the frequency of knowledge transfer. 


\section{Conclusions and Countermeasures}

4.1. Research Conclusions. In this paper, the theory of acoustic wave transfer is introduced, the circular knowledge radiator model is introduced as a model of knowledge transfer in a knowledge alliance, and the relationships among the factors affecting knowledge transfer are studied. Based on this research, the following conclusions can be drawn. First, the effect of knowledge transfer in a knowledge alliance is affected by the number of enterprises in the knowledge alliance, the frequency of knowledge transfer in the knowledge alliance, and the relationship distance between the knowledge sending enterprise and each knowledge receiving enterprise. These three influencing factors are interrelated and exert interdependent effects on knowledge transfer. Second, the knowledge field corresponding to knowledge transfer can be divided into a near-field region and a far-field region based on the knowledge Rayleigh distance. In the near field, the curve representing the knowledge influence amplitude shows more variation, whereas in the far field, the knowledge influence amplitude decreases monotonically with increasing distance. The vicinity of the knowledge Rayleigh distance is the region with the best knowledge transfer behaviour. The knowledge Rayleigh distance of a knowledge alliance is affected by the number of enterprises participating in the alliance and the frequency of knowledge transfer. Third, an increase in either the number of enterprises in the knowledge alliance or the frequency of knowledge transfer will cause the knowledge Rayleigh distance to increase. Additionally, the oscillation of the influence amplitude curve in the near field will increase, and the amplitude of the knowledge influence in the far field will decrease more gradually with distance. Therefore, ensuring a relatively large number of knowledge alliance members and a high knowledge transfer frequency is beneficial for adjusting the appropriate relationship distance to achieve a satisfactory knowledge transfer effect in a knowledge alliance. Fourth, compared with the frequency of knowledge transfer, the number of enterprises in the alliance has a more significant impact on knowledge transfer. Therefore, a reasonable grasp of the influence of the number of alliance members is the key to improving the efficiency of knowledge transfer.

The main insights of this paper are as follows: firstly, the simulation analysis found that the number of knowledge alliance enterprises and the frequency of knowledge transfer have mutual influence, and the impact on knowledge transfer is not independent. Secondly, when the number of enterprises and the frequency of knowledge transfer are large, knowledge alliance needs to maintain a stable and relatively intimate relationship distance. Finally, knowledge transfer in knowledge alliance has the best effect at the knowledge Rayleigh distance point.

4.2. Policy Implications. The above conclusions have certain significance for guiding the development of alliance strategies for knowledge alliances and efforts to improve the knowledge transfer efficiency in knowledge alliances, as follows:

(1) Government level. The number of enterprises in an alliance has a significant impact on the knowledge transfer effect. Both increasing the number of alliance members and increasing the frequency of knowledge transfer are beneficial for maintaining an appropriate relationship distance in the knowledge transfer process. Therefore, the government should adopt policies to encourage enterprises to establish large-scale knowledge alliances and promote efficient interenterprise communication methods to meet the needs of more levels of knowledge transfer and ensure knowledge transfer efficiency in knowledge alliances. Additionally, the effective operation of knowledge alliances requires a reasonably sound policy environment. The government should standardize intellectual property protection mechanisms and an alliance contract system in accordance with market conditions and improve relevant laws, regulations, and related policies. In addition, the government should satisfy the requirements for the effective operation of knowledge alliances, support the effective operation of knowledge alliances, and promote the smooth development of knowledge alliances [78].

(2) Alliance level. The best knowledge transfer effect can be achieved for a knowledge receiving enterprise for which the relationship distance between the knowledge sending enterprise and the knowledge receiving enterprise is near the Rayleigh distance of the knowledge field. Under different conditions, the partner that best matches the knowledge transfer characteristics of a knowledge alliance will be different. The collaborative objective of knowledge transfer is directly related to the efficiency and quality of knowledge transfer within a knowledge alliance. Such an alliance should establish a suitable matching mechanism and carefully select collaboration partners. Screening based on this matching mechanism prior to knowledge transfer will be beneficial for helping a knowledge alliance find suitable partners. Additionally, an alliance should focus on communication among its partners. Formal mechanisms for communication between alliance members and between the alliance and knowledge transfer partners should be established, and an atmosphere of informal communication should be created. It is necessary to establish and improve the mechanisms of trust, conflict management, and punishment among the alliance members to apply a controlling force on improper behaviour within the knowledge alliance, manage the relationships between the partners, and strengthen their trust $[79,80]$. In addition, an alliance should adopt different strategies for different knowledge transfer 
processes and rationally regulate the number of enterprises participating in knowledge transfer within the alliance and the appropriate frequency of knowledge transfer in accordance with the distance between the knowledge sending enterprise and the knowledge receiving enterprise to adapt to different knowledge transfer needs.

4.3. Main Contributions of This Paper. The main theoretical contributions of this paper are as follows:

(1) In the research field of strategic alliances and knowledge transfer $[13,21,49,51,81-83]$, some scholars realized the similarity between knowledge and acoustic waves, but there are few literatures on metaphor research using the acoustic model. In this paper, the theory of acoustic wave is applied to metaphorical analysis of knowledge transfer in knowledge alliance, and the circular radiator model is introduced into the research field of knowledge transfer, which provides a new research tool for the research field of strategic alliance and knowledge transfer.

(2) When studying the partner matching of strategic alliance, most scholars emphasize the matching among members in structure, strategy, and culture $[8,23,79,84-87]$ and paid insufficient attention to the characteristics and capabilities of alliances. Only a few of them discussed the choice of partners from the perspective of knowledge classification or enterprise type $[9,10,82]$. From the perspective of alliance characteristics and capabilities, this paper explores the influence of the number of alliance enterprises on knowledge transfer. This paper studies knowledge transfer in knowledge alliance from a new perspective, expands the research perspective in the field of knowledge transfer, and enriches the research content of alliance characteristics and alliance capability dimensions in strategic alliance.

(3) In the research field of knowledge transfer, many literatures emphasized the relationship management among members of strategic alliances $[14,15,45,46,88-91]$ but did not link the appropriate relationship distance among alliance members to alliance characteristics and alliance capability dimensions. This paper points out that there is an appropriate relationship distance for knowledge transfer in knowledge alliances with different number of members and different frequencies of knowledge transfer. This paper also expands the research paradigm of the single factor of knowledge transfer in the knowledge alliance and analyzes the complex interaction relationship among the three influencing factors of the number of knowledge alliance members, knowledge transfer frequency, and relationship distance.
4.4. Deficiencies and Outlook. This paper uses the metaphor model to study knowledge transfer in knowledge alliance, which has certain theoretical and practical value. However, due to the limitations of the author's ability and time, there are still some shortcomings. On the one hand, this paper studies the interaction among the three influencing factors in the process of knowledge transfer. Other factors may also have an impact on knowledge transfer in knowledge alliance, such as the impact of policy factors and knowledge attributes in the process of knowledge transfer. On the other hand, the simulation method used in this paper is not combined with statistical data. The author will do more in-depth and detailed research in the future.

In addition, the author believes that this paper can provide reference for future research in the following three aspects:

(1) For the strategic alliances, knowledge transfer, and complexity science research, the use of metaphorical research methods can provide new research directions. In this paper, based on metaphor analysis, concepts and models in the theory of acoustic wave transfer are introduced into the research field of knowledge transfer, which has important implications to future research.

(2) This paper explores the influence of alliance characteristics and capabilities on the matching degree of partner selection in knowledge transfer and analyzes the role of the number of alliance enterprises in this process. It expands the research perspective of knowledge transfer. Based on this paper, researchers can do more in-depth research on the number of alliance enterprises.

(3) In this paper, the appropriate relationship distance among alliance members is connected on alliance characteristics and alliance capability dimensions, which expands the research paradigm of a single factor of knowledge transfer in knowledge alliance. In the research field of alliance relationship management, researchers can further consider the complex role of multiple factors.

\section{Appendix}

Knowledge Field Knowledge Influence Function Deduction and Simplification Process. Because $r \gg a, r_{A} \approx r-$ $\rho \cos \varphi \sin \theta$. In the denominator of the integrand function, the authors take $r_{A} \longrightarrow r$, and in the exponential factor of the integrand, the authors take $r_{A} \longrightarrow r-\rho \cos \varphi \sin \theta$; thus, the authors can obtain

$$
\begin{aligned}
\Phi(r) & =e^{j \omega t} \iint_{S} \frac{v_{0}}{2 \pi} \frac{e^{-j k r_{A}}}{r_{A}} d s \\
& =\frac{v_{0}}{2 \pi} \frac{e^{j(\omega t-k r)}}{r} \int_{0}^{a} \int_{0}^{2 \pi} e^{j k \rho \cos \varphi \sin \theta} \rho d \varphi d \rho .
\end{aligned}
$$

Because 


$$
\begin{aligned}
J_{0}(x) & =\frac{1}{2 \pi} \int_{0}^{2 \pi} e^{ \pm j x \cos \varphi} \mathrm{d} \varphi, \\
x J_{1}(x) & =\int x J_{0}(x) \mathrm{d} x, \\
\Phi(r) & =\frac{v_{0}}{2 \pi} \frac{e^{j(\omega t-k r)}}{r} \int_{0}^{a} \int_{0}^{2 \pi} e^{j k \rho \cos \varphi \sin \theta} \rho \mathrm{d} \varphi \mathrm{d} \rho \\
& =\frac{v_{0}}{2 \pi} \frac{e^{j(\omega t-k r)}}{r} 2 \pi \int_{0}^{a} J_{0}(k \rho \sin \theta) \rho \mathrm{d} \rho \\
& =\frac{e^{j(\omega t-k r)} v_{0}}{r} \int_{0}^{a} \frac{J_{0}(k \rho \sin \theta) k \rho \sin \theta}{(k \sin \theta)^{2}} \mathrm{~d} k \rho \sin \theta \\
& =\frac{e^{j(\omega t-k r)} v_{0}}{r} \frac{J_{1}(k \rho \sin \theta) k \rho \sin \theta}{(k \sin \theta)^{2}} \mid \rho=a \\
& =\frac{e^{j(\omega t-k r)} v_{0} a^{2}}{r} \frac{J_{1}(k a \sin \theta)}{(k a \sin \theta)^{2}},
\end{aligned}
$$

where $J_{0}(x)$ and $J_{1}(x)$ represent the 0 th-order and 1 st-order Bessel functions, respectively.

Thus, according to

$$
p(r)=\rho_{0} \frac{\partial \Phi(r)}{\partial r}
$$

we can obtain the distribution function describing the influence of the knowledge alliance in the knowledge field as follows:

$$
p(r)=\frac{j \omega \rho_{0} a^{2} v_{0} e^{j(\omega t-k r)}}{2 r} \frac{2 J_{1}(k a \sin \theta)}{(k a \sin \theta)},
$$

where $p(r)$ denotes the influence of the circular knowledge radiator on knowledge transfer at any point in the knowledge field and $\rho_{0}$ denotes the density of the environment, which affects the diffusion of knowledge waves.

The knowledge wave number is an important concept. Based on the knowledge wave number, the authors can obtain many variables related to knowledge wave transfer to characterize the specific knowledge transfer situation, such as the knowledge wave frequency $f$, the knowledge wavelength $\lambda$, the knowledge wave cycle $T$, and the knowledge wave velocity $c$, where the knowledge wave frequency $f$ and the knowledge wave cycle $T$ are reciprocal to each other, that is, $f=1 / T$. The knowledge wave frequency $f$ represents the number of knowledge waves sent per unit time. The knowledge wave cycle $T$ represents how long it takes to send a knowledge wave. The knowledge wave velocity $c$ represents the speed of knowledge wave propagation in the environment. The knowledge wavelength $\lambda$ represents the distance travelled by a knowledge wave over the course of one period. Clearly, the relationship among $c, f$, and $\lambda$ is $c=f \lambda$. The knowledge wave number $k$ represents the number of knowledge wave periods within the length of $2 \pi$, that is, $k=2 \pi / \lambda$; through variable substitution, $k=2 \pi f / c$ can be obtained. The relationship between the knowledge wave angular frequency $\omega$ and the knowledge wave frequency $f$ is $\omega=2 \pi f=2 \pi / T$. Therefore, the knowledge wave angular frequency $\omega$ can also be understood as the number of complete knowledge wave periods produced in a time duration of $2 \pi$. The knowledge wave angular frequency $\omega$, the knowledge wave frequency $f$, and the knowledge wave number $k$ are closely related. Through substitution, expressions written in terms of these quantities can instead be expressed in terms of the knowledge wavelength $\lambda$ and the knowledge wave velocity $c$.

From formula (A.6), the authors can observe that this influence distribution function varies with $\theta$ in addition to $r$. That is, at the same distance in space, the distribution of the knowledge influence is different at different angles. Taking $\theta=$ $0^{\circ}$ as the initial direction value, a knowledge field directivity function $\Phi$ can be obtained by normalizing the knowledge influence distribution function for different angles:

$$
D(\theta)=\frac{|\widetilde{p}(z, \theta)|}{|\widetilde{p}(z, \theta=0)|}=\left|\frac{2 J_{1}(k a \sin \theta)}{(k a \sin \theta)}\right| .
$$

Observing formula (A.6), the authors can find that formula (A.6) is more complicated and contains too many variables, which makes it difficult to conduct simulation research directly. Therefore, the formula needs to be simplified to some extent, and the underlying laws of knowledge transfer are sought by studying changes in several core variables. Based on this, this paper assumes that, during the knowledge transfer process of the knowledge alliance, the target knowledge receiving enterprise is on the centre axis of the knowledge circular radiator. This means that the target knowledge receiving enterprise corresponds to this knowledge transfer and has the highest degree of matching with this knowledge transfer. The selection of coordinate axes can be simplified to Figure 10 .

The velocity potential function in the knowledge field is known to be $\Phi(r)=e^{j \omega t} \iint_{S}\left(v_{0} / 2 \pi\right)\left(e^{-j k r_{A} / r_{A}}\right) \mathrm{d} s$, where $r_{A}$ represents the distance between a knowledge element of the circular knowledge radiator and the point $M$ in the knowledge field at which the knowledge receiving enterprise is located. $S$ denotes the circular face of the knowledge radiator of radius $a$. The knowledge receiving enterprise is located at a point $z$ on the axis, where $r_{A}=\sqrt{z^{2}+\rho^{2}}$. The authors can obtain the corresponding function describing the velocity potential in the knowledge field as follows:

$$
\begin{aligned}
\Phi(z) & =e^{j \omega t} \iint_{S} \frac{v_{0}}{2 \pi} \frac{e^{-j k r_{A}}}{r_{A}} \mathrm{~d} s \\
& =e^{j \omega t} \frac{v_{0}}{2 \pi} \int_{0}^{2 \pi} \int_{0}^{a} \frac{e^{-j k \sqrt{z^{2}+\rho^{2}}}}{\sqrt{z^{2}+\rho^{2}}} \rho \mathrm{d} \rho \mathrm{d} \varphi \\
& =e^{j \omega t} \frac{-v_{0}}{j k}\left(e^{-j k \sqrt{z^{2}+a^{2}}}-e^{-j k z}\right) \\
& =e^{j \omega t} \frac{j v_{0}}{k}\left[e^{-j(k / 2)\left(\sqrt{z^{2}+a^{2}}-z\right)}-e^{j(k / 2)\left(\sqrt{z^{2}+a^{2}}-z\right)}\right] e^{-j(k / 2)\left(\sqrt{z^{2}+a^{2}}-z\right)} \\
& =\frac{-2 v_{0}}{k} \sin \left[\frac{k}{2}\left(\sqrt{z^{2}+a^{2}}-z\right)\right] e^{j\left[\omega t-(k / 2)\left(\sqrt{z^{2}+a^{2}}+z\right)\right] .}
\end{aligned}
$$

From formula (A.5), the distribution function describing the knowledge influence of the circular knowledge radiator 
on a knowledge receiving enterprise in the knowledge alliance can be obtained as follows:

$$
p(r)=-j \omega \rho_{0} \frac{2 v_{0}}{k} \sin \left[\frac{k}{2}\left(\sqrt{z^{2}+a^{2}}-z\right)\right] e^{j\left[\omega t-(k / 2)\left(\sqrt{z^{2}+a^{2}}+z\right)\right]} .
$$

It is worth noting that the influence on knowledge transfer within the knowledge field is equivalent to the knowledge waves. With a continuous cyclical variation over time, the influence amplitude $P_{m}(r)$ represents the distribution of the knowledge transfer influence of the circular knowledge radiator on the knowledge receiving enterprises as a function of the relationship distance as follows:

$$
p_{m}(r)=\left|\sin \left[\frac{k}{2}\left(\sqrt{z^{2}+a^{2}}-z\right)\right]\right| .
$$

Simulation Analysis Supplement. Figures 11(a)-11(c) show the distributions of the influence amplitude for knowledge transfer when $k=2$ and $a=2,5,10$, respectively. Figures 12(a)-12(b) show the distributions when $k=5$ and $a=2,5,10$, respectively. By comparing Figures $8(\mathrm{a})-8(\mathrm{c})$ with Figures 11 and 12, it can be seen that the effect of an identical change in the $a$ value is different for different $k$ values. When the value of $k$ is small, the influence of an increase in the $a$ value is also relatively small; the Rayleigh distance changes by approximately 15 units from $a=2$ to $a=10$. When $k=2$ and $k=5$, the same change in $a$ causes the Rayleigh distance to change by approximately 30 and 80 units, respectively. Similarly, with smaller $k$ values, the nearfield oscillation in the knowledge field and the far field influence decrease. It is not difficult to find that an increase in the $k$ value will amplify the influence of larger $a$ values on knowledge transfer. As seen from the numerical values and the graphs, the relationship between an increase in the $k$ value and the influence of the $a$ value is approximately proportional, with a coefficient of 1 .

Similarly, the next step in exploring the influence of different $a$ values is to determine the effect of changes in the $k$ value on knowledge transfer for different fixed values of $a$. Figures 13(a)-13(c) show the distributions of the influence amplitude for knowledge transfer when $a=2$ and $k=2,5,10$, respectively. Figures $14(\mathrm{a})-14$ (c) show the distributions when $a=5$ and $k=2,5,10$, respectively. By comparing Figures 9(a)-9(c) with Figures 13 and 14, it can be seen that the effect of $a$ on the influence of the $k$ value is similar to the effect of $k$ on the influence of the $a$ value. For different values of $a$, the same change in the $k$ value has different effects on knowledge transfer. The larger the $a$ value is, the greater the change in the influence amplitude distribution that is caused by a change in the $k$ value. However, compared with the previous case, it is obvious that a change in the $k$ value without a change in the $a$ value has a smaller influence on knowledge transfer. For example, a comparison of the knowledge influence amplitude curves for $k=2$ and $a=2, k=2$ and $a=10$, and $k=10$ and $a=2$ shows that the curve is more sensitive to changes in the $a$ value.

\section{Data Availability}

The data used to support the findings of this study are available from the corresponding author upon request.

\section{Conflicts of Interest}

The authors declare that there are no conflicts of interest regarding the publication of this paper.

\section{Acknowledgments}

This work was supported by the National Natural Science Foundation of China (71774036), an MOE (Ministry of Education of China) Project of Humanities and Social Sciences (18YJC630245), the Social Science Foundation of Heilongjiang Province (17GLH21 and 18GLB023), and the Natural Science Foundation of Heilongiang Province (QC2018088).

\section{References}

[1] A. M. Petruzzelli, "Trading knowledge for status: conceptualizing R\&D alliance formation to achieve ambidexterity," Technological Forecasting \& Social Change, vol. 145, pp. 36-42, 2019.

[2] R. C. Basole and H. Park, "Interfirm collaboration and firm value in software ecosystems: evidence from cloud computing," IEEE Access, vol. 66, no. 3, pp. 365-380, 2019.

[3] F. Jiang and X. Jiang, "The contingent value of resource complementarity for alliance performance: evidence from Chinese manufacturing firms," IEEE Transactions on Engineering Management, vol. 66, no. 3, pp. 354-367, 2019.

[4] F. Alipour and R. Karimi, "Mediation role of innovation and knowledge transfer in the relationship between learning organization and organizational performance," International Journal of Business and Social Science, vol. 2, no. 19, pp. 144-147, 2011.

[5] Inkpen, "The management of international joint ventures: anorganziational learning perspective," Journal of Knowledge Management, vol. 35, no. 8, pp. 120-134, 1995.

[6] H. Hottenrott and C. Lopes-Bento, "Quantity or quality? Knowledge alliances and their effects on patenting," Industrial and Corporate Change, vol. 24, no. 5, pp. 981-1011, 2015.

[7] B. Bos, D. Faems, and F. Noseleit, "Alliance concentration in multinational companies: examining alliance portfolios, firm structure, and firm performance," Strategic Management Journal, vol. 38, no. 11, pp. 2298-2309, 2017.

[8] W. Sierzchula, S. Bakker, K. Maat, and B. van Wee, "Alliance formation in the automobile sector during an era of ferment," Creativity and Innovation Management, vol. 24, no. 1, pp. 109-122, 2015.

[9] R. B. Bouncken and V. Fredrich, "Learning in coopetition: alliance orientation, network size, and firm types," Journal of Business Research, vol. 69, no. 5, pp. 1753-1758, 2016.

[10] S. Yayavaram, M. K. Srivastava, and M. Sarkar, "Role of search for domain knowledge and architectural knowledge in alliance partner selection," Strategic Management Journal, vol. 39, no. 8, pp. 2277-2302, 2018.

[11] S. Zhang, C. Yuan, and Y. Wang, "The impact of industryuniversity-research alliance portfolio diversity on firm innovation: evidence from Chinese manufacturing firms," Sustainability, vol. 11, no. 8, p. 2321, 2019. 
[12] Y. Su, F.-y. Wang, and X.-l. An, "Coupling mechanism and coupling degree measurement model of shipbuilding industry cluster," Polish Maritime Research, vol. 23, no. 1, pp. 78-85, 2016.

[13] K. Choi, R.-J. B. Jean, and D. Kim, "The impacts of organizational learning capacities on relationship-specific innovations," International Marketing Review, vol. 36, no. 6, pp. 1042-1066, 2019.

[14] R. Milagres and A. Burcharth, "Knowledge transfer in interorganizational partnerships: what do we know?" Business Process Management Journal, vol. 25, no. 1, pp. 27-68, 2019.

[15] J. Sun, X. Ren, and C. J. Anumba, "Analysis of knowledgetransfer mechanisms in construction Project cooperation networks," Journal of Management in Engineering, vol. 35, no. 2, Article ID 04019061, 2019.

[16] G. R. T. White, S. Cicmil, A. Upadhyay, N. Subramanian, V. Kumar, and A. Dwivedi, "The soft side of knowledge transfer partnerships between universities and small to medium enterprises: an exploratory study to understand process improvement," Production Planning \& Control, vol. 30, no. 10-12, pp. 907-918, 2019.

[17] N. D. Tho, "Knowledge transfer from business schools to business organizations: the roles absorptive capacity, learning motivation, acquired knowledge and job autonomy," Journal of Knowledge Management, vol. 21, no. 5, pp. 1240-1253, 2017.

[18] M. I. R. Bravo, M. Stevenson, A. R. Moreno, and F. J. L. Montes, "Absorptive and desorptive capacity configurations in supply chains: an inverted U-shaped relationship," International Journal of Production Research, vol. 58, no. 7, pp. 2036-2055, 2020.

[19] N. D. Tho and N. T. M. Trang, "Can knowledge be transferred from business schools to business organizations through inservice training students? SEM and fsQCA findings," Journal of Business Research, vol. 68, no. 6, pp. 1332-1340, 2015.

[20] V. Fredrich, R. B. Bouncken, and S. Kraus, "The race is on: configurations of absorptive capacity, interdependence and slack resources for interorganizational learning in coopetition alliances," Journal of Business Research, vol. 101, pp. 862-868, 2019.

[21] M. K. Srivastava, D. R. Gnyawali, and D. E. Hatfield, "Behavioral implications of absorptive capacity: the role of technological effort and technological capability in leveraging alliance network technological resources," Technological Forecasting and Social Change, vol. 92, pp. 346-358, 2015.

[22] G. Szulanski, D. Ringov, and R. J. Jensen, "Overcoming stickiness: how the timing of knowledge transfer methods affects transfer difficulty," Organization Science, vol. 27, no. 2, pp. 304-322, 2016.

[23] E. de Wit-de Vries, W. A. Dolfsma, H. J. van der Windt, and M. P. Gerkema, "Knowledge transfer in university-industry research partnerships: a review," The Journal of Technology Transfer, vol. 44, no. 4, pp. 1236-1255, 2019.

[24] C. Kolympiris, S. Hoenen, and P. G. Klein, "Learning by seconding: evidence from national science foundation rotators," Organization Science, vol. 30, no. 3, pp. 528-551, 2019.

[25] L. Masi, C. Herba, and P. Garel, "Projet pilote: exploration de l'utilisation d'Internet et des médias sociaux chez un groupe d'adolescents ayant participé à Espace Transition," Annales Médico-Psychologiques, Revue Psychiatrique, vol. 177, no. 4, pp. 319-326, 2019.

[26] M. Hemmert, "The relevance of inter-personal ties and interorganizational tie strength for outcomes of research collaborations in South Korea," Asia Pacific Journal of Management, vol. 36, no. 2, pp. 373-393, 2019.
[27] S. Jiang and H. Chen, "Examining patterns of scientific knowledge diffusion based on knowledge cyber infrastructure: a multi-dimensional network approach," Scientometrics, vol. 121, no. 3, pp. 1599-1617, 2019.

[28] M. T. Hansen and M. L. Mors, "Knowledge sharing in organizations: multiple networks, multiple phases," Academy of Management Journal, vol. 48, no. 5, pp. 776-793, 2005.

[29] C. Løvås, C. Niu, and J. Han, "Spatial dynamics of intercity technology transfer networks in China's three urban agglomerations: a patent transaction perspective," Sustainability, vol. 11, no. 6, p. 1647, 2019.

[30] S. Hasan and R. Koning, "Prior ties and the limits of peer effects on startup team performance," Strategic Management Journal, vol. 40, no. 9, pp. 1394-1416, 2019.

[31] J. J. Li, L. Poppo, and K. Z. Zhou, "Relational Mechanisms formal contracts and local knowledge acquisition by international subsidiaries," Strategic Management Journal, vol. 31, no. 4, pp. 349-370, 2010.

[32] J. Jiang, R. K. Goel, and X. Zhang, "Knowledge flows from business method software patents: influence of firms global social networks," The Journal of Technology Transfer, vol. 44, no. 4, pp. 1070-1096, 2019.

[33] Y.-F. Yen, J.-F. Tseng, and H.-K. Wang, "Exploring the mediating role of trust on the relationship between guanxi and knowledge sharing: a social network perspective," Asia Pacific Journal of Human Resources, vol. 52, no. 2, pp. 173-192, 2014.

[34] X. Liu, H. S. Jiang, and C. A. LarsonRoco, "Modeling knowledge diffusion in scientific innovation networks: an institutional comparison between China and US with illustration for nanotechnology," Scientometrics, vol. 105, no. 3, pp. 1953-1984, 2015.

[35] G. Fang, Q. Zhou, and J. Wu, "The relationship between network capabilities and innovation performance," Industrial Management \& Data Systems, vol. 119, no. 8, pp. 1638-1654, 2019.

[36] X.-L. Qi, Z. Zhou, and X. Yu, "Predicting users' willingness to diffuse healthcare knowledge in social media," Information Technology \& People, vol. 32, no. 4, pp. 1044-1064, 2019.

[37] R. Cowan and N. Jonard, "Network structure and the diffusion of knowledge," Journal of Economic Dynamics and Control, vol. 28, no. 8, pp. 1557-1575, 2004.

[38] H. Kim and Y. Park, "Structural effects of R\&D collaboration network on knowledge diffusion performance," Expert Systems with Applications, vol. 36, no. 5, pp. 8986-8992, 2009.

[39] F. Tang, J. Mu, and D. L. Maclachlan, "Disseminative capacity, organizational structure and knowledge transfer," Expert Systems with Applications, vol. 37, no. 2, pp. 1586-1593, 2010.

[40] T. Konno, "Network effect of knowledge spillover: scale-free networks stimulate R\&D activities and accelerate economic growth," Physica A: Statistical Mechanics and Its Applications, vol. 458, pp. 157-167, 2016.

[41] H. F. de Arruda, F. N. Silva, and L. d. F. Costa, "Knowledge acquisition: a complex networks approach," Information Sciences, vol. 421, pp. 154-166, 2017.

[42] B. Amancio, S.-h. Han, and Z. Jin, "Modeling of knowledge transmission by considering the level of forgetfulness in complex networks," Physica A: Statistical Mechanics and Its Applications, vol. 451, pp. 277-287, 2016.

[43] H. Wang, J. Wang, and L. Ding, "Knowledge transmission model with consideration of self-learning mechanism in complex networks," Applied Mathematics and Computation, vol. 304, pp. 83-92, 2017.

[44] H. Wei, J. Wang, M. Small et al., "Knowledge transmission model with differing initial transmission and retransmission 
process," Physica A: Statistical Mechanics and Its Applications, vol. 507, pp. 478-488, 2018.

[45] Y.-C. Park, B.-K. Kim, and S. Lee, "The effects of alliance governance on knowledge acquisition and alliance performance of Korean firms," Asian Journal of Technology Innovation, vol. 25, no. 3, pp. 428-446, 2017.

[46] Q. Yang, Y. Liu, and Y. Li, "How do an alliance firm's strategic orientations drive its knowledge acquisition? Evidence from Sino-foreign alliance partnership," Journal of Business \& Industrial Marketing, vol. 34, no. 2, pp. 505-517, 2019.

[47] L. Xiao, S. H. Xu, and X. X. Zeng, "Design and analysis of knowledge transfer in the process of university-industry collaborative innovation based on social network theory," Journal of Internet Technology, vol. 19, no. 4, pp. 1155-1167, 2018.

[48] Z. Li, Z. Wang, C. Liu, and Z. Jiang, "The knowledge flow analysis on multimedia information using evolutionary game model," Multimedia Tools and Applications, vol. 78, no. 1, pp. 965-994, 2019.

[49] K. Kavusan, N. G. Noorderhaven, and G. M. Duysters, "Knowledge acquisition and complementary specialization in alliances: the impact of technological overlap and alliance experience," Research Policy, vol. 45, no. 10, pp. 2153-2165, 2016.

[50] C. Park and I. Vertinsky, "Reverse and conventional knowledge transfers in international joint ventures," Journal of Business Research, vol. 69, no. 8, pp. 2821-2829, 2016.

[51] C. R. Wu, E. Zapevalova, Y. W. Chen, and F. Li, "Time optimization of multiple knowledge transfers in the big data environment," Computers, Materials \& Continua, vol. 54, no. 3, pp. 269-285, 2018.

[52] M. Lin and Q. Zhang, "Time scales of knowledge transfer with learning and forgetting," Physica A: Statistical Mechanics and Its Applications, vol. 525, pp. 704-713, 2019.

[53] F. B. Korbi and M. Chouki, "Knowledge transfer in international asymmetric alliances: the key role of translation, artifacts, and proximity," Journal of Knowledge Management, vol. 21, no. 5, pp. 1272-1291, 2017.

[54] A. Capaldo and A. Messeni Petruzzelli, "Origins of knowledge and innovation in R\&D alliances: a contingency approach," Technology Analysis \& Strategic Management, vol. 27, no. 4, pp. 461-483, 2015.

[55] T. Caner and B. B. Tyler, "The effects of knowledge depth and scope on the relationship between R\&D alliances and new product development," Journal of Product Innovation Management, vol. 32, no. 5, pp. 808-824, 2015.

[56] H. L. Ju, S. J. Zhang, S. K. Zhao, and X. W. Ju, "Knowledge transfer capacity of universities and knowledge transfer success: evidence from university-industry collaborations in China," International Journal of Technology Management: The Journal of the Technology Management of Technology, Engineering Management, Technology Policy and Strategy, vol. 71, no. 3-4, pp. 278-300, 2016.

[57] Y. Su and B. Liu, "Synergetics of enterprise innovation systems based on a three-variable oscillation reaction," IEEE Access, vol. 7, no. 1, pp. 150598-150608, 2019.

[58] T. S. Kuhn, Metaphor in Science, Cambridge University Press, Cambridge, UK, 1993.

[59] T. Brown, "Making Truth: metaphor in science," Journal of Chemical Education, vol. 80, no. 8, p. 880, 2003.

[60] M. Hesse, Revolutions and Reconstructions in the Philosophy of Science, University of Notre Dame Press, Notre Dame, IN, USA, 1980.
[61] A. I. Miller, "Metaphor and scientific creativity," Metaphor and Analogy in the Sciences, vol. 1, 2000.

[62] M. Black, "Models and metaphors: studies in language and philosophy," Philosophy and Phenomenological Research, vol. 23, no. 2, 1968.

[63] D. M. B. Jones, Models, Metaphors and Analogies, Blackwell Publishers Ltd, Oxford, UK, 2008.

[64] N. Da Costa and S. French, Science and Partial Truth: A Unitary Approach to Models and Scientific Reasoning, Oxford University Press, Oxford, UK, 2003.

[65] K. D. Forbus, D. Gentner, and K. Law, "MAC/FAC: a model of similarity-based retrieval," Cognitive Science, vol. 19, no. 2, pp. 141-205, 1995.

[66] G. Y. Guo and Y. Y. Yang, "Metaphor modeling in scientific representation: based on contextual realism," Philosophical Studies, vol. 61, no. 2, pp. 110-116, 2016.

[67] M. B. Hesse, Models and Analogies in Science, University of Notre Dame Press, Notre Dame, IN, USA, 1966.

[68] M. Daniela and Bailer-Jones, Scientific Models in Philosophy of Science, Pittsburgh Press, Pittsburgh, PL, USA, 2009.

[69] M. Black, "More about metaphor," Dialectica, vol. 31, no. 3-4, pp. 431-457, 1977.

[70] L. D. Ritchie, "Context and Connection in Metaphor," Hampshire, Palgrave, MacMillan, New York, NY, USA, 2006.

[71] M. Bradie, "Science and metaphor," Biology \& Philosophy, vol. 14, no. 2, pp. 159-166, 1999.

[72] C. Liu, "Approximations, idealizations, and models in statistical mechanics," Erkenntnis, vol. 60, no. 2, pp. 235-263, 2004.

[73] M. Guarini, "Bohm's metaphors, causality, and the quantum potential,” Erkenntnis, vol. 59, no. 1, pp. 77-95, 2003.

[74] T. G. Amin, F. Jeppsson, and J. Haglund, "Arrow of time: metaphorical construals of entropy and the second law of thermodynamics," Science Education, vol. 96, no. 5, pp. 818-848, 2012.

[75] Z. Strömdahl, H. Xu, and G. Yuan, "Modeling study of knowledge diffusion in scientific collaboration networks based on differential dynamics: a case study in graphene field," Physica A: Statistical Mechanics and Its Applications, vol. 524, pp. 375-391, 2019.

[76] R. N. Giere and S. French, "Explaining science: a cognitive approach," American Journal of Physics, vol. 57, no. 6, pp. 572-573, 1989.

[77] Y. W. French and Y. P. Wei, "Mechanism \& empirical analysis on knowledge-wave diffusion effect between enterprise in alliance," Science of Science and Management of S.\& T, vol. 31, no. 5, pp. 142-149, 2010.

[78] Y. Su and X. L. An, "Application of threshold regression analysis to study the impact of regional technological innovation level on sustainable development," Renewable \& Sustainable Energy Reviews, vol. 89, pp. 27-32, 2018.

[79] S. V. Devarakonda and J. J. Reuer, "Knowledge sharing and safeguarding in R\&D collaborations: the role of steering committees in biotechnology alliances," Strategic Management Journal, vol. 39, no. 7, pp. 1912-1934, 2018.

[80] X. Jiang, Y. Bao, Y. Xie, and S. Gao, "Partner trustworthiness, knowledge flow in strategic alliances, and firm competitiveness: a contingency perspective," Journal of Business Research, vol. 69, no. 2, pp. 804-814, 2016.

[81] J. J. Reuer and N. Lahiri, "Searching for alliance partners: effects of geographic distance on the formation of $R \& D$ collaborations," Organization Science, vol. 25, no. 1, pp. 283-298, 2014. 
[82] V. Aggarwal and M. Kapoor, "Innovation growth from knowledge transfer in international strategic alliances," Journal of Strategy and Management, vol. 11, no. 4, pp. 483-496, 2018.

[83] C. Marco, M. Myriam, and T. Salvatore, "Firm strategic behavior and the measurement of knowledge flows with patent citations," Strategic Management Journal, vol. 40, no. 7, pp. 1040-1069, 2019.

[84] M. R. Lee and Y.-C. Lan, "Toward a unified knowledge management model for SMEs," Expert Systems with Applications, vol. 38, no. 1, pp. 729-735, 2011.

[85] V. Dutot, F. Bergeron, and L. Raymond, "Information management for the internationalization of SMEs: an exploratory study based on a strategic alignment perspective," International Journal of Information Management, vol. 34, no. 5, pp. 672-681, 2014.

[86] M. G. Martinsons, R. M. Davison, and Q. Huang, "Strategic knowledge management failures in small professional service firms in Chinafirms in China," International Journal of Information Management, vol. 37, no. 4, pp. 327-338, 2017.

[87] S. Huang, J. Chen, W. Ye, and K. Wang, "The effect of external partner heterogeneity on open innovation: the moderating role of the technological regime," Technology Analysis \& Strategic Management, vol. 31, no. 5, pp. 593-605, 2019.

[88] R. Du, S. Ai, P. Abbott, and Y. Zheng, "Contextual factors, knowledge processes and performance in global sourcing of IT services," Journal of Global Information Management, vol. 19, no. 2, pp. 1-26, 2011.

[89] C. Park, I. Vertinsky, and M. Becerra, "Transfers of tacit vs. explicit knowledge and performance in international joint ventures: the role of age," International Business Review, vol. 24, no. 1, pp. 89-101, 2015.

[90] T. Pedersen, G. Soda, and D. Stea, "Globally networked: intraorganizational boundary spanning in the global organization," Journal of World Business, vol. 54, no. 3, pp. 169180, 2019.

[91] D. Faems, B. Bos, F. Noseleit, and B. Leten, "Multistep knowledge transfer in multinational corporation networks: when do subsidiaries benefit from unconnected sister alliances?" Journal of Management, vol. 46, no. 3, pp. 414-442, 2020. 